\title{
Utilization of Monosaccharides by Hungateiclostridium thermocellum ATCC 27405 through Adaptive Evolution
}

\author{
Dung Minh Ha-Tran ${ }^{1,2,3}\left[\right.$, Trinh Thi My Nguyen ${ }^{2}$, Shou-Chen Lo ${ }^{2, *,+} \mathbb{C}$ and Chieh-Chen Huang ${ }^{2,4, *,+}$ \\ 1 Molecular and Biological Agricultural Sciences Program, Taiwan International Graduate Program, \\ Academia Sinica and National Chung Hsing University, Taipei 11529, Taiwan; hatranminhdung@gmail.com \\ 2 Department of Life Sciences, National Chung Hsing University, Taichung 40227, Taiwan; \\ mytrinhnguyen0410@gmail.com \\ 3 Graduate Institute of Biotechnology, National Chung Hsing University, Taichung 40227, Taiwan \\ 4 Innovation and Development Center of Sustainable Agriculture, National Chung Hsing University, \\ Taichung 40227, Taiwan \\ * Correspondence: scl@dragon.nchu.edu.tw (S.-C.L.); cchuang@dragon.nchu.edu.tw (C.-C.H.) \\ + Mailing Address: Life Sciences Building 4F. R.403, No.145, Xingda Rd., Taichung 402, Taiwan.
}

check for updates

Citation: Ha-Tran, D.M.; Nguyen, T.T.M.; Lo, S.-C.; Huang, C.-C. Utilization of Monosaccharides by Hungateiclostridium thermocellum ATCC 27405 through Adaptive Evolution. Microorganisms 2021, 9 , 1445. https://doi.org/10.3390/ microorganisms 9071445

Academic Editor:

María-Isabel González-Siso

Received: 15 June 2021

Accepted: 2 July 2021

Published: 4 July 2021

Publisher's Note: MDPI stays neutral with regard to jurisdictional claims in published maps and institutional affiliations.

Copyright: (c) 2021 by the authors. Licensee MDPI, Basel, Switzerland. This article is an open access article distributed under the terms and conditions of the Creative Commons Attribution (CC BY) license (https:/ / creativecommons.org/licenses/by/ $4.0 /)$.

\begin{abstract}
Hungateiclostridium thermocellum ATCC 27405 is a promising bacterium for consolidated bioprocessing with a robust ability to degrade lignocellulosic biomass through a multienzyme cellulosomal complex. The bacterium uses the released cellodextrins, glucose polymers of different lengths, as its primary carbon source and energy. In contrast, the bacterium exhibits poor growth on monosaccharides such as fructose and glucose. This phenomenon raises many important questions concerning its glycolytic pathways and sugar transport systems. Until now, the detailed mechanisms of $H$. thermocellum adaptation to growth on hexose sugars have been relatively poorly explored. In this study, adaptive laboratory evolution was applied to train the bacterium in hexose sugarsbased media, and genome resequencing was used to detect the genes that got mutated during adaptation period. RNA-seq data of the first culture growing on either fructose or glucose revealed that several glycolytic genes in the Embden-Mayerhof-Parnas pathway were expressed at lower levels in these cells than in cellobiose-grown cells. After seven consecutive transfer events on fructose and glucose $(\sim 42$ generations for fructose-adapted cells and $\sim 40$ generations for glucose-adapted cells), several genes in the EMP glycolysis of the evolved strains increased the levels of mRNA expression, accompanied by a faster growth, a greater biomass yield, a higher ethanol titer than those in their parent strains. Genomic screening also revealed several mutation events in the genomes of the evolved strains, especially in those responsible for sugar transport and central carbon metabolism. Consequently, these genes could be applied as potential targets for further metabolic engineering to improve this bacterium for bio-industrial usage.
\end{abstract}

Keywords: Hungateiclostridium thermocellum; Clostridium thermocellum; Ruminiclostridium thermocellum; adaptive laboratory evolution; RNA-seq; whole genome sequencing; cellulosomal genes; EMP pathway; monosaccharides; hexose sugars

\section{Introduction}

Hungateiclostridium thermocellum (Clostridium thermocellum, Ruminiclostridium thermocellum, Acetivibrio thermocellus), a thermophilic, gram-positive, anaerobic bacterium, exhibits a strong capacity to efficiently degrade crystalline cellulose. H. thermocellum produces various industrially important fermentation products, such as ethanol, acetic acid, lactic acid, and hydrogen, thus understanding its responses to different carbon sources helps improve production of the desired end-products. To date, several studies focusing on the regulatory mechanisms of specific genes of interest [1-7] and genomic [8,9], transcriptomic [10-14], metabolomic [15,16], proteomic [17-20], and integrated omics [21-24] studies 
have been performed to expand our knowledge of $H$. thermocellum genetics, gene expression, metabolism, and physiology. However, most previous studies utilized the preferred substrates of $H$. thermocellum, such as cellobiose $[9,21,24]$, crystalline cellulose $[10,19]$, cellobiose and crystalline cellulose in combination $[17,25,26]$, or pretreated switchgrass and Populus [12], pretreated yellow poplar and cellobiose [14]. The accumulation of glucose at the end of substrate fermentation was noted in a previous study [27] and the presence of glucose in medium, in turn, inhibits the catalytic activity of cellulosomes [28]. Accordingly, improving the utilization of glucose by $H$. thermocellum is beneficial for cellulosic bioethanol production. Although the chemical formula of glucose and fructose is the same, differences in their molecular formations leads to changes in cellulase production of glucose- and fructose-adapted cells. This phenomenon was first observed by Johnson et al. [29] decades ago, however, it has not been elucidated on a point of view of mRNA expression level. Since $H$. thermocellum always demonstrates impaired growth on comparatively simple monosaccharides such as glucose, fructose, or sorbitol [29-31], some research groups were interested in investigating the production of glycolytic enzymes [32], the production of cellulase [29], sugar transport systems [33,34], mutation of the bacterium [30], and carbon metabolism [31] in this bacterium when growing on these unfavored substrates. $H$. thermocellum experiences a long lag phase when growing on these substrates, which Nochur et al. [30] assumed might be due to the time needed for genetic changes in the bacterial genome to allow it to grow on fructose or glucose. However, these authors did not determine which genes got mutated during the extended lag period. In another study, Nochur et al. speculated that the long lag phase of fructose-adapted cells (FAs) and glucose-adapted cells (GAs) could be due to the lower intracellular $\mathrm{pH}$ in these cells than in cellobiose-grown cells (CGs) [31]. However, this could not explain the newly acquired characteristics of the evolved phenotypes, especially in terms of genetic and mRNA expression changes.

Adaptive laboratory evolution (ALE) has been widely used to better understand the basic mechanisms of molecular evolution and the genomic changes that accumulate in microbial populations during long-term selection under specific growth conditions [35]. With rapid advances in transcriptomic profiling and next-generation sequencing (NGS), phenotype-genotype correlations can be easily obtained [36]. In a previous ALE study, H. thermocellum was cultured in Populus hydrolysate, a medium that contains various compounds that are toxic to the bacterium. After 117 transfers from 5-17.5\% (v/v) Populus hydrolysate, 73 mutations were identified [8]. These mutations were found to be related to cellular repair and energy metabolism, which helped the bacterium grow better than the wild type in the toxic medium [11]. A two-stage adaptive evolution was applied to train an engineered $H$. thermocellum AG553 (DSM1313 $\Delta h p t \Delta h y d G \Delta l d h \Delta p f l \Delta p t a-a c k$ ) for a faster growth and higher ethanol titer [37]. As a result, the resulting evolved strain LL1210 can produce $22.4 \pm 1.4 \mathrm{~g} / \mathrm{L}$ ethanol from $60 \mathrm{~g} / \mathrm{L}$ cellulose. Recently, Holwerda et al. found that a mutation in the adhE gene induced by ALE allowed $H$. thermocellum to grow better and achieve higher ethanol yield [9]. In the present study, the cellobiose-grown cells were used as starting materials to inoculate into fructose-, glucose-, or cellobiosecontaining medium. After the first culture event, the fructose-adapted cells (FAs1) and glucose-adapted cells (GAs1) were collected for RNA-seq, with the cellobiose-grown cells (CGs1) used as the control, to elucidate the responses of $H$. thermocellum to nutritional stress. The Embden-Meyerhof-Parnas (EMP) pathway was particularly emphasized since this is the predominant glycolytic route in this bacterium [16]. Subsequently, the ALE strategy was applied to improve growth rate and hexose sugars metabolism of FAs1 and GAs1. After seven serial transfers, genome resequencing was carried out to identify genetic changes that occurred in the genome of the evolved FAs8 and GAs8 strains. To date, only one recently published study by Yayo and coworkers [38] has used genomic analysis combined with reverse engineering to elucidate the mechanism of adaptation of H. thermocellum to hexose sugars. In the study of Yayo et al. [38], H. thermocellum DSM 1313 was cultured in carbon-limited chemostats with increasing glucose or fructose 
concentration and decreasing cellobiose concentration setting. Our approach, however, is quite different from their study, since H. thermocellum ATCC 27,405 was cultured in a static batch culture with sole fructose, glucose, or cellobiose added to the growth medium from the beginning of the fermentation. Our transcriptomic profiles of FAs1, FAs8, GAs1, GAs8, and CGs1 and the genome resequencing data of the evolved strains FAs8 and GAs8 aid to support and confirm the results of the previous studies, thereby shedding more light on the interesting abovementioned issues and broadening our knowledge in this area.

\section{Materials and Methods}

\subsection{H. thermocellum ATCC 27,405 Growth Conditions and Medium Preparation}

One liter of the modified GS-2 medium contained $1.5 \mathrm{~g} \mathrm{KH}_{2} \mathrm{PO}_{4}, 2.9 \mathrm{~g} \mathrm{~K}_{2} \mathrm{HPO}_{4}, 3 \mathrm{~g}$ sodium citrate tribasic dihydrate $\left(\mathrm{Na}_{3} \mathrm{C}_{6} \mathrm{H}_{5} \mathrm{O}_{7}\right), 2.1 \mathrm{~g}$ urea, $5 \mathrm{~g}$ 3-(N-morpholino) propanesulfonic acid (MOPS), $2 \mathrm{mg}$ resazurin, and $1 \mathrm{~g}$ L-cysteine. A 10-fold trace salt solution contained $26 \mathrm{mg} \mathrm{MgCl}_{2}, 11.3 \mathrm{mg} \mathrm{CaCl}$, and $0.125 \mathrm{mg} \mathrm{FeSO}_{4} .7 \mathrm{H}_{2} \mathrm{O}$. A 100-fold vitamin solution contained $2 \mathrm{mg}$ pyridoxine hydrochloride, $0.2 \mathrm{mg}$ biotin, $0.4 \mathrm{mg}$ p-aminobenzoic acid and $0.2 \mathrm{mg}$ vitamin B12 [39]. Trace salt and vitamin solutions were sterilized using a $0.22-\mu \mathrm{m}$ filter (StarTech, Taiwan). All solutions were prepared with distilled water from an EcoQ Combo (LionBio, Taiwan). The pH of the GS-2 medium was adjusted to 7.2 using $5 \mathrm{M}$ $\mathrm{NaOH}$ and purged extensively with pure nitrogen gas to create an anaerobic environment. GS-2 medium was autoclaved at $121{ }^{\circ} \mathrm{C}$ for $20 \mathrm{~min}$, and $1 \%(v / v)$ trace salt solution and $1 \%(v / v)$ vitamin solution were added to the modified GS-2 when the medium was cooled to $50{ }^{\circ} \mathrm{C}$.

To prepare the seed inoculum, $H$. thermocellum was grown in modified GS-2 medium supplemented with cellobiose $(5 \mathrm{~g} / \mathrm{L})$ until the stationary phase was reached $\left(\mathrm{OD}_{660} \sim 0.7\right)$ and then inoculated $1 \%(v / v)$ into the same medium containing either glucose $(10 \mathrm{~g} / \mathrm{L})$, fructose $(10 \mathrm{~g} / \mathrm{L})$, or cellobiose $(5 \mathrm{~g} / \mathrm{L})$. Three independent sets of CGs1, FAs1, and GAs1 were performed for growth pattern determination, gas and ethanol measurements, residual reducing sugar tests, and cellulosomal enzyme assays. Cells were grown in batch culture at $60{ }^{\circ} \mathrm{C}$ in $250-\mathrm{mL}$ serum bottles containing $100 \mathrm{~mL}$ of modified GS-2 medium. Cell growth was monitored daily based on the measurement of optical density at $\mathrm{A}_{660}$ using a GeneQuant 1300 spectrophotometer (Biochrom, Holliston, MA, USA). The cell mass was quantified from the pellet protein as described by Zhang and Lynd [40], except that the Bradford assay, with bovine serum albumin (BSA) (Sigma-Aldrich, St. Louis, MI, USA) as the standard, instead of Peterson's method. Briefly, $1 \mathrm{~mL}$ of culture broth was centrifuged using a Hitachi Tabletop centrifuge CT15RE (Hitachi Koki Co., Ltd., Tokyo, Japan) at $12,800 \times g$ for $10 \mathrm{~min}$. The pellet was washed with distilled water once, and $1 \mathrm{~mL}$ of $0.2 \mathrm{M}$ $\mathrm{NaOH}$ and $1 \%$ SDS were added to the pellet. The sample was incubated at $28{ }^{\circ} \mathrm{C}$ for $30 \mathrm{~min}$ with occasional stirring. The pellet was resuspended, and $0.25 \mathrm{~mL}$ of $0.8 \mathrm{M} \mathrm{HCl}$ was added and mixed well to neutralize the sample. After centrifugation at $12,800 \times g$ for $5 \mathrm{~min}$, the protein in the supernatant was determined. One $\mathrm{A}_{660}$ unit corresponds to $0.85 \mathrm{~g} / \mathrm{L}$ of cell biomass and carbon molarity in cell biomass was calculated based on the elemental composition of cells $\left(\mathrm{C}_{5} \mathrm{H}_{8} \mathrm{O}_{2} \mathrm{~N}\right)$, which corresponds to a molecular weight of $114.12 \mathrm{~g} / \mathrm{mol}[41]$.

\subsection{Phosphoric Acid Swollen Cellulose and Cellulosome Isolation}

Amorphous cellulose was prepared by phosphoric acid swelling as described by Zhang et al. [42]. Cellulosomes were isolated from $100 \mathrm{~mL}$ of cellobiose-, glucose- and fructose-fermentation broth collected at late stationary phase using the affinity digestion protocol described by St Brice et al. [43]. Briefly, cell-free broth was recovered by centrifuging the fermentation broth at $12,800 \times g$ for $40 \mathrm{~min}$ at $4{ }^{\circ} \mathrm{C}$ using a Hermle Z326K centrifuge (Benchmark, Wehingen, Germany). The supernatant was decanted, and the $\mathrm{pH}$ was adjusted to 7.0 with $2 \mathrm{M} \mathrm{NaOH}$ as evaluated with a S20 SevenEasy ${ }^{\mathrm{TM}} \mathrm{pH}$ meter (Mettler-Toledo, PoMe, Australia). The cell-free broth was incubated with amorphous cellulose $\left(10 \mathrm{mg} / 100 \mathrm{~mL}\right.$ of cell-free broth) overnight at $4{ }^{\circ} \mathrm{C}$ to allow the binding of the 
cellulosomes to the cellulose. Amorphous cellulose with bound enzymes was centrifuged at $12,800 \times \mathrm{g}$ for $30 \mathrm{~min}$ at $4^{\circ} \mathrm{C}$, and the pellet was resuspended in $20 \mathrm{~mL}$ dialysis buffer (50 mM Tris-base, $10 \mathrm{mM} \mathrm{CaCl}, 5 \mathrm{mM}$ dithiothreitol (DTT), pH 7.0). The amorphous cellulose suspension was then dialyzed in membrane bags (Spectrum ${ }^{\mathrm{TM}}$ Spectra $/ \mathrm{POR}^{\mathrm{TM}} 1$ MWCO 6-8000, Fisher Scientific, Hampton, NH, USA) at $55^{\circ} \mathrm{C}$ against two liters of distilled water to initiate amorphous cellulose degradation by the enzyme. Distilled water was changed every $60 \mathrm{~min}$ to avoid inhibition of the cellulosomes by the degradation products. After $5 \mathrm{~h}$ of incubation, the transparent suspension was centrifuged at $3000 \times g$ for $30 \mathrm{~min}$ at $4{ }^{\circ} \mathrm{C}$, decanted and stored at $-20{ }^{\circ} \mathrm{C}$ for protein and activity analysis. Total protein of the extracted cellulosomes was measured with a Bio-Rad Bradford protein assay with BSA as a standard.

\subsection{Avicelase, CMCase, and Xylanase Assays}

The assays were performed as described by Zhang et al. [44]. Briefly, $4.1 \mathrm{~mL}$ of the well-suspended Avicel solution (2.44 g of dry Avicel $/ 100 \mathrm{~mL}$ distilled water) and $0.5 \mathrm{~mL}$ of Tris- $\mathrm{HCl}$ buffer (0.5 M Tris; $\mathrm{pH} 7.0 ; 0.1 \mathrm{M} \mathrm{CaCl}_{2}$, and optional $1.5 \%(w / v)$ sodium azide $\left(\mathrm{NaN}_{3}\right)$ were added into $16 \times 125 \mathrm{~mm}$ anaerobic culture Hungate tubes. The tubes were sealed with 9-mm screw caps with butyl rubber stoppers, held under vacuum, and flushed with pure nitrogen at least 3 times for 5 min each. DTT at $0.5 \mathrm{M}$ was added to the tubes $(0.1 \mathrm{~mL} /$ tube) before the enzyme activity assay. The tubes were prewarmed in a water bath at $60{ }^{\circ} \mathrm{C}$ for $10 \mathrm{~min}$, and $0.3 \mathrm{~mL}$ of the extracted cellulosome solution dilution series was added to the tubes. After the first $10 \mathrm{~min}$ of adsorption and reaction, $0.5 \mathrm{~mL}$ of sample (well-mixed Avicel suspension) was withdrawn as the starting point, followed by removal of an additional $0.5 \mathrm{~mL}$ every $60 \mathrm{~min}$. The reactions were stopped by transferring the tubes to an ice water bath, and then the samples were placed in precooled 1.5-mL microcentrifuge tubes. The samples were centrifuged at $13,000 \times g$ for $3 \mathrm{~min}$. The net soluble sugar released during the hydrolysis process was calculated by subtracting the amount of sugar measured at the starting point, and enzyme activity was determined based on the linear correlation between sugar released and enzyme concentration. In the CMCase assay, $2 \%(w / v)$ carboxymethylcellulose (CMC) was dissolved in citrate buffer (50 $\mathrm{mM}$, $\mathrm{pH}$ 4.8). A volume of $0.5 \mathrm{~mL}$ of the diluted enzyme was added into the Hungate tubes. One half $\mathrm{mL}$ of the CMC solution was then added to the test tubes, and the tube contents were mixed well by pipetting. The mixture was incubated at $50{ }^{\circ} \mathrm{C}$ for $30 \mathrm{~min}$, and $3 \mathrm{~mL}$ of DNS solution was added into the test tubes to stop the reaction. The Hungate test tubes were boiled for $5 \mathrm{~min}$ in boiling water and then placed in an ice water bath. The xylanase activity of purified cellulosomes was measured by the colorimetric assay described by Ribeiro et al. [45] using birchwood xylan as the substrate, and the reducing sugars were determined using the DNS method with xylose as a control. Briefly, the reaction mixture $(0.05 \mathrm{~mL}$ substrate $(1 \% w / v)$ in $50 \mathrm{mM}$ sodium acetate buffer, $\mathrm{pH}$, and $0.01 \mathrm{~mL}$ of enzyme solution) was incubated at $70{ }^{\circ} \mathrm{C}$ in a water bath for $5 \mathrm{~min}$. The reaction was stopped by adding $0.1 \mathrm{~mL}$ of DNS and immediately boiling for $5 \mathrm{~min}$. Quantification of the reducing sugars released as the result of enzyme activity was estimated by $\mathrm{A}_{540}$ measurements using a Beckman Coulter-PARADIGM ${ }^{\mathrm{TM}}$ microplate reader (Beckman Coulter, Chaska, MN, USA), where one unit of enzymatic activity was defined as the amount of the extracted cellulosomes that produced $1 \mu \mathrm{mol} / \mathrm{min}$ of reducing sugars.

\subsection{Measurement of Residual Reducing Sugar, Carbon Dioxide, and Ethanol}

Reducing sugars were measured using the DNS method [46], and the standard curves were constructed using 5-fold serial dilutions of a pure chemical sample. The standard curves for glucose, fructose and cellobiose assays were built separately, as these sugars have different reactivities with the DNS reagent [47]. To prepare samples for ethanol and reducing sugar determination, $1 \mathrm{~mL}$ of fermentation broth was centrifuged at $12,800 \times \mathrm{g}$ for $10 \mathrm{~min}$ at $4{ }^{\circ} \mathrm{C}$. The pellet was discarded, and the supernatant was filtered using a $0.22-\mu \mathrm{m}$ filter (StarTech, Taipei, Taiwan). $\mathrm{CO}_{2}$ was measured daily, but ethanol and reducing sug- 
ars were analyzed using samples that were taken at late stationary phase. These major fermentation end-products were determined by a GC Agilent 7890A (Agilent Technologies, Santa Clara, CA, USA) equipped with a J\&W 122-3232: $30 \mathrm{~m} \times 250 \mu \mathrm{m} \times 0.25 \mu \mathrm{m}$ DB-FFAP column, with nitrogen as the carrier gas at a flow rate of $30 \mathrm{~mL} / \mathrm{min}$. For ethanol measurement, the front inlet was used, the detector was kept at $225^{\circ} \mathrm{C}$, and the oven was heated from $50{ }^{\circ} \mathrm{C}$ to $150{ }^{\circ} \mathrm{C}\left(50-100{ }^{\circ} \mathrm{C}\right.$ at a ramp rate of $30^{\circ} \mathrm{C} / \mathrm{min}$ and $100-150{ }^{\circ} \mathrm{C}$ at a ramp rate of $20^{\circ} \mathrm{C} / \mathrm{min}$ ). For $\mathrm{CO}_{2}$ measurement, the back inlet was used, the detector was kept at $225^{\circ} \mathrm{C}$, and the oven was operated isothermally at $50{ }^{\circ} \mathrm{C}$.

\subsection{RNA Isolation and Library Preparation and Sequencing}

Two independent sets of CGs1, FAs1 and GAs1 from two biological replicates and one set of each FAs8 or GAs8 from the two biological replicates were harvested at the late stationary phase for RNA-seq as described in the Figure 1. All 4 sets of biological replicates were used for RT-qPCR of selected genes. Total RNA was extracted using TRIzol (R) Reagent (Invitrogen, Waltham, MA, USA) according to the instruction manual. Purified RNA was quantified at $\mathrm{OD}_{260 \mathrm{~nm}}$ using an ND-1000 spectrophotometer (NanoDrop Technology, Wilmington, DE, USA) and quality checked using a Bioanalyzer 2100 instrument (Agilent Technologies, CA, USA) with an RNA 6000 LabChip kit (Agilent Technologies, CA, USA).

All RNA sample preparation procedures were carried out according to Illumina's official protocol. Agilent's SureSelect Strand-Specific RNA Library Preparation Kit was used for library construction, followed by size selection with AMPure XP beads (Beckman Coulter, Carlsbad, CA, USA). The sequences were determined using Illumina sequencingby-synthesis (SBS) technology (Illumina, CA, USA). Sequencing data (FASTQ reads) were generated based on the Illumina Conversion program bcl2fastq v2.20. The raw counts of FAs1, GAs1, CGs1 were presented in Table S1, and those of FAs8, GAs8, and CGs1 were shown in Table S2.

\subsection{Differential Gene Expression Analysis}

All RNA-seq data analyses and graphics production were performed using R (ver. 3.6.1). The expression levels were calculated as reads per kilobase per million reads (RPKM). The Bioconductor package edgeR (ver. 3.28.1) [48] was used for differential expression analysis. The edgeR was built based on a parametric method that performs DE analysis based on the assumption that the inputted raw data follow a negative binomial distribution. Genes with significant low expression levels (raw count $<3$ or RPKM value $<0.3$ ) in the treated samples (FAs1 and GAs1) and the control sample (CGs1) were excluded. Genes with $\geq 2$-fold change or $\leq 0.5$-fold change ( $\log _{2}$-fold change $\geq 1$ or log2-fold change $\leq-1$ ) and a false discovery rate (FDR) of $p<0.01$ were considered significantly differentially expressed.

\subsection{Sample Preparation for Genomic Analysis}

The evolved populations that had been serially passaged on fructose and glucose were used for genome resequencing. Each transfer included about 100 -fold dilution $(1 \%, v / v)$, or approximately 5 generations. Two independent sets from two biological replicates of the evolved strains FAs8 or Gas8 (8th transfer $\sim 42$ generations for FAs8 and $\sim 40$ generations for GAs8), which were considered the endpoint strains, were harvested, and stored at $-80{ }^{\circ} \mathrm{C}$. Genomic DNA was extracted by a WelPrep DNA kit (Welgene Biotech, Taipei, Taiwan) according to the manufacturer's instructions. DNA samples with OD 260/280 in the range of 1.8 2.0 were quantity/quality assessed using the Agilent Genomic DNA ScreenTape assay in conjunction with the 4200 TapeStation system (Agilent Technologies, CA, USA). 

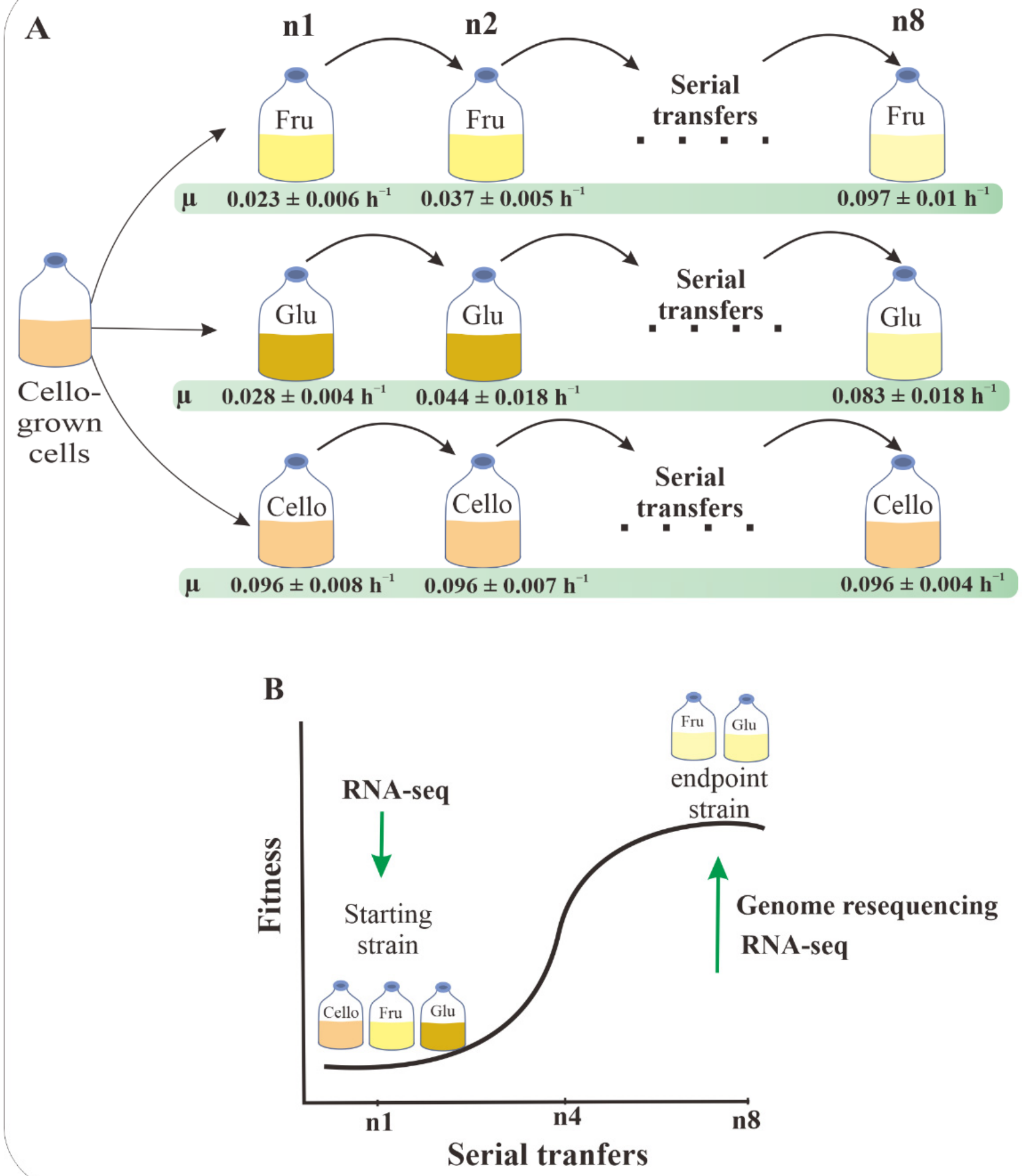

Figure 1. Schematic diagram of the present study. (A) Adaptive laboratory evolution was applied to FAs1 and GAs1 to improve their growth on fructose and glucose, respectively. After $\sim 40$ generations, growth rates of FAs8 and GAs8 were dramatically increased. (B) Starting strains FAs1, GAs1, and CGs1 at the late stationary phase were used for RNA-seq and the end-point strains FAs8, GAs8 were used for genomic analysis and RNA-seq. 


\subsection{Library Construction and Sequencing}

Total DNA $(10 \mu \mathrm{g})$ was sonicated using a Covaris M220 focused ultrasonicator (Covaris, Woburn, MA, USA) to sizes ranging from 400 to $500 \mathrm{bp}$. DNA sizing was checked using the Agilent D1000 ScreenTape assay with the 4200 TapeStation system. Approximately $0.5 \mu \mathrm{g}$ fragmented DNA was end-repaired, A-tailed and adaptor-ligated following the Illumina TruSeq DNA preparation protocol. After library construction, samples were mixed with MiSeq Reagent Kit v3 (600 cycles) and loaded onto a MiSeq cartridge. Then, a $2 \times 300$ bp paired-end sequencing run was performed on the MiSeq sequencer platform (Illumina, San Diego, CA, USA).

\subsection{Read Mapping, Variant Calling and Annotation}

The raw sequences generated from the sequencer first went through a filtering process to obtain good quality reads. FASTP was implemented to trim bases or remove reads according to quality scores. The reference genome sequence and annotation GFF file were downloaded from the NCBI RefSeq genome database. The trimmed reads were aligned against the reference genome using the bwa aligner with the BWA-MEM algorithm. Then, the Picard tool MarkDuplicates was used to remove duplicate alignments. The GATK tool HaplotypeCaller was used for variant detection. Finally, snpEff was used to perform variant annotation.

\section{Results and Discussion}

3.1. Growth Patterns, Sugar Utilization, Cellulosomal Enzyme Activities and Ethanol Productivity of CGs1, FAs1, and GAs1

As expected, the culture of $H$. thermocellum ATCC 27,405 on hexose sugars took much time due to a defeat in central carbon metabolism and a lack of an appropriate monosaccharide transport system. After a long lag phase of adaptation, H. thermocellum eventually used glucose or fructose as a sole carbon source and energy for its growth (Figure 2A). This finding is in agreement with the results of Hernandez [33], Johnson et al. [29], and Yayo et al. [38], which showed that the H. thermocellum bacterium could grow on fructose and glucose only after an extended lag time. However, the final cell biomass of FAs1 and GAs1 was still lower than that of CGs1, in contrast to the results obtained in the work of Johnson et al. [29], who found that the final H. thermocellum cell density of FAs1, GAs1 and CGs1 was comparable. As the most powerful hydrolytic machinery that has been identified in a microorganism to date, $H$. thermocellum cellulosomal function, composition, and regulation patterns have been a popular research topic for decades [1-4,7,12,14,17,18,25,26,28,29,43,49-57]. Regarding cellulosomal enzyme activities, FAs1 cellulosomes expressed the highest exoglucanase, endoglucanase, and xylanase activities, followed by CGs1 cellulosomes (Figure 2B). Surprisingly, the lowest cellulosomal enzyme activities were found in GAs1, even though $H$. thermocellum growing on glucose is not subject to carbon catabolite repression [29]. The observed GAs1 enzyme activities were in agreement with a study by Zhang et al. [28], who used kinetic models and empirical experiments to prove that glucose was an inhibitor of the H. thermocellum cellulosome. Other reports also indicated that cellobiose was a strong inhibitor of cellulosomes and cellulases $[53,58]$. These previous studies could partly explain the low activities of cellulosomal enzymes derived from CGs1 and GAs1 compared to those derived from FAs1. As fructose and glucose are unfavored carbon sources for H. thermocellum growth, it is not surprising that their consumption was limited, representing large amounts of fructose and glucose remained in the culture broths at the end of the fermentation. Cellobiose, in contrast, is the preferred carbon source of H. thermocellum, thus, this disaccharide was rapidly consumed by the bacterium, enabling robust growth and an effective end-product formation. Consequently, the ethanol productivity, sugar consumption, and cell biomass of CGs1 were significantly greater than those of FAs1 and GAs1 (Figure 2C). 


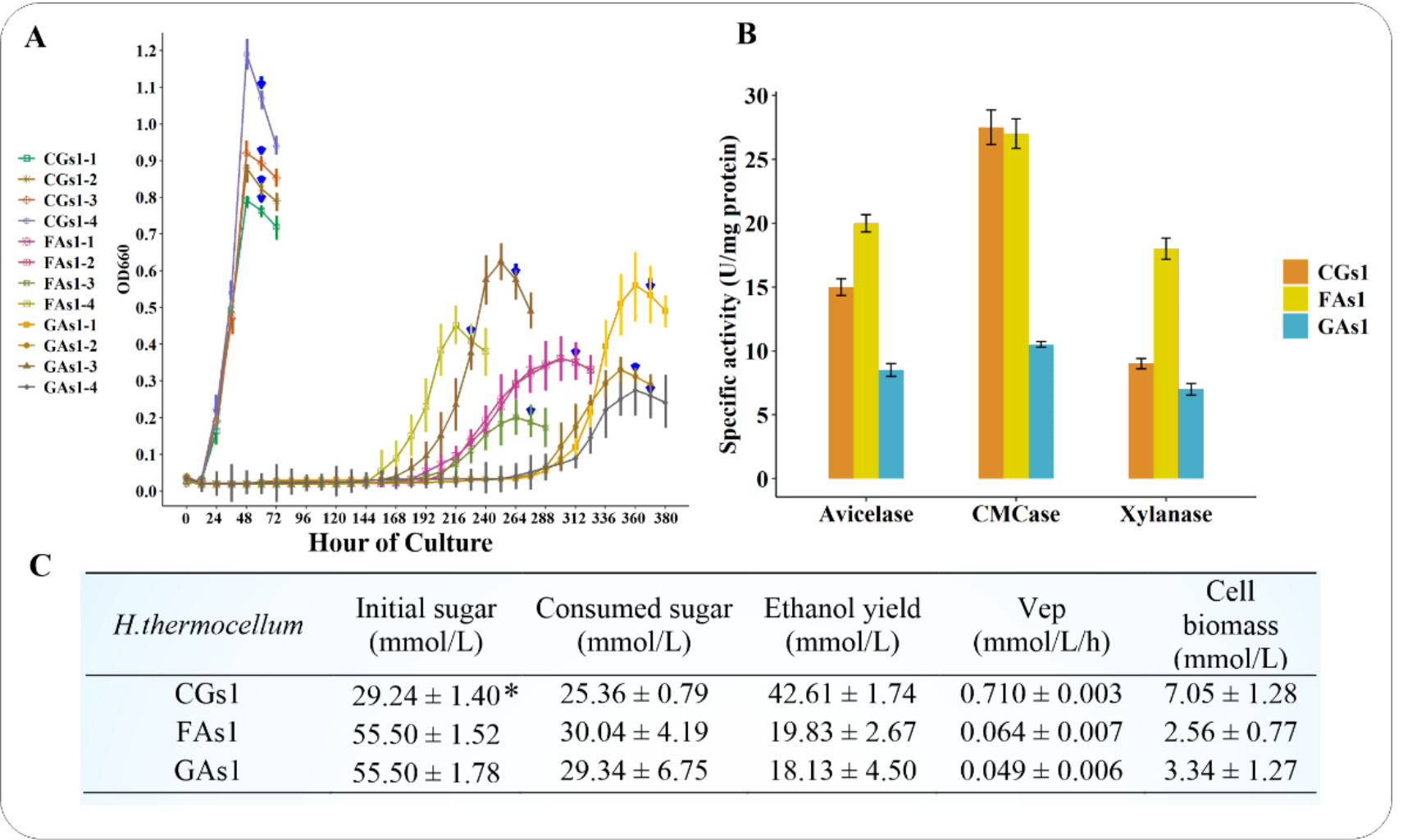

Figure 2. H. thermocellum growth patterns, cellulosomal enzyme activity, sugar consumption, and ethanol fermentation. (A) Growth profiles of CGs1, FAs1, and GAs1 in four biological replicates. The blue arrowheads indicate the sampling points used for RNA-seq, RT-qPCR, and cellulosome isolation. (B) Specific enzyme activity of the H. thermocellum cellulosome. (C) Sugar consumption, ethanol yield, volumetric ethanol productivity, and cell biomass of CGs1, FAs1, and GAs1. All data in Figure $2 \mathrm{~B}, \mathrm{C}$ represent the mean \pm sd of biological triplicate. Note: * mmol glucose equivalents; Vep: Volumetric ethanol productivity $(\mathrm{mmol} / \mathrm{L} / \mathrm{h})$.

\subsection{Adaptive Laboratory Evolution}

In the beginning, the cellobiose-grown cells at exponential phase $\left(\mathrm{OD}_{660} \sim 0.6\right)$ were inoculated $(1 \%, v / v)$ into fresh fructose- or glucose-based medium. A dark yellow color appeared in the FAs1 fermentation broth, simultaneously with some motile granules in the medium, suggesting a stress response of the organism to fructose. Similarly, the yellowish color also appeared in the GAs1 fermentation broth. However, the color soon became light yellow and then milky white after some serial transfers. From the first to the seventh transfer, the duration of the lag phase gradually decreased (from approximately $168 \pm 22 \mathrm{~h}$ for FAs1 and $216 \pm 51 \mathrm{~h}$ for GAs1 to less than $12 \mathrm{~h}$ for both FAs8 and GAs8). After some transfers, the bacterial biomass of the intermediate strains constantly increased relative to that of FAs1, along with an improved ability to consume fructose, as shown in Table 1. Consequently, the ethanol yield of the end-point strain FAs8 was comparable with that of the parent strain FAs1, but it exhibited a dramatically improved growth rate and a significantly greater biomass relative to FAs1 (Table 1).

A similar pattern was observed in the intermediate strain GAs, reflected in a greater biomass and faster glucose consumption compared to the first culture GAs1 (Table 1). We observed a longer lag phase on glucose feeding than that on fructose, whereas the opposite observation was recorded by Yayo et al. [38], with a 42 h-lag phase for glucose-grown cells and a longer than 80-h-lag phase for fructose-grown cells. The higher cell biomass on fructose rather than on glucose observed in our study was in accordance with Yayo and colleagues' finding [38]. Glucose consumption during fermentation and the yield of ethanol, however, were lower than those of FAs8 (Table 1). 
Table 1. Hexose sugars consumption, ethanol and $\mathrm{CO}_{2}$ production, cell biomass and ethanol yield after seven sequential transfer events.

\begin{tabular}{|c|c|c|c|c|c|}
\hline Fructose-Adapted Cells & $\begin{array}{c}\text { Consumed } \\
\text { Sugar }(\mathrm{mmol} / \mathrm{L})\end{array}$ & $\begin{array}{l}\text { Ethanol } \\
\text { (mmol/L) }\end{array}$ & $\mathrm{CO}_{2}(\mathrm{mmol} / \mathrm{L})$ & $\begin{array}{l}\text { Cell Biomass } \\
(\mathrm{mmol} / \mathrm{L})\end{array}$ & $\begin{array}{c}\text { Ethanol Yield } \\
\text { (mmol Eth/mmol Sugar) }\end{array}$ \\
\hline FAs1 & $30.04 \pm 4.19$ & $19.83 \pm 2.67$ & $3.24 \pm 0.46$ & $2.56 \pm 0.77$ & $0.66 \pm 0.03$ \\
\hline FAs2 & $15.24 \pm 1.67$ & $7.610 \pm 1.13$ & $1.79 \pm 0.24$ & $3.68 \pm 1.24$ & $0.50 \pm 0.02$ \\
\hline FAs3 & $17.94 \pm 2.63$ & $8.110 \pm 1.68$ & $2.14 \pm 0.28$ & $5.22 \pm 2.4$ & $0.45 \pm 0.02$ \\
\hline FAs4 & $18.22 \pm 2.80$ & $8.260 \pm 1.36$ & $2.09 \pm 0.31$ & $5.54 \pm 2.43$ & $0.45 \pm 0.03$ \\
\hline FAs5 & $22.58 \pm 1.59$ & $11.30 \pm 1.21$ & $2.74 \pm 0.22$ & $6.04 \pm 1.12$ & $0.50 \pm 0.02$ \\
\hline FAs6 & $26.21 \pm 2.50$ & $11.97 \pm 0.98$ & $2.83 \pm 0.14$ & $8.33 \pm 1.14$ & $0.46 \pm 0.04$ \\
\hline FAs7 & $30.37 \pm 1.84$ & $14.45 \pm 1.24$ & $2.98 \pm 0.28$ & $9.32 \pm 0.83$ & $0.48 \pm 0.05$ \\
\hline FAs8 & $34.23 \pm 2.74$ & $17.54 \pm 1.06$ & $3.68 \pm 0.29$ & $9.77 \pm 1.37$ & $0.51 \pm 0.06$ \\
\hline \multicolumn{6}{|l|}{ Glucose-Adapted Cells } \\
\hline GAs1 & $29.34 \pm 6.75$ & $18.13 \pm 4.50$ & $4.42 \pm 1.10$ & $3.34 \pm 1.27$ & $0.62 \pm 0.04$ \\
\hline GAs2 & $17.19 \pm 2.23$ & $8.800 \pm 3.20$ & $2.85 \pm 1.25$ & $3.75 \pm 1.83$ & $0.51 \pm 0.02$ \\
\hline GAs3 & $18.51 \pm 2.92$ & $9.130 \pm 1.20$ & $3.03 \pm 0.70$ & $4.48 \pm 0.66$ & $0.49 \pm 0.03$ \\
\hline GAs4 & $21.05 \pm 2.12$ & $9.910 \pm 1.72$ & $3.15 \pm 0.80$ & $5.87 \pm 2.36$ & $0.47 \pm 0.04$ \\
\hline GAs5 & $21.52 \pm 3.47$ & $10.00 \pm 1.30$ & $3.24 \pm 0.49$ & $6.30 \pm 1.73$ & $0.46 \pm 0.04$ \\
\hline GAs6 & $23.41 \pm 2.50$ & $11.83 \pm 1.23$ & $3.29 \pm 0.42$ & $6.18 \pm 2.25$ & $0.51 \pm 0.02$ \\
\hline GAs7 & $23.76 \pm 3.50$ & $12.28 \pm 3.85$ & $3.35 \pm 0.82$ & $6.13 \pm 2.86$ & $0.52 \pm 0.06$ \\
\hline GAs8 & $24.88 \pm 2.74$ & $12.35 \pm 1.18$ & $3.41 \pm 0.41$ & $7.27 \pm 4.49$ & $0.50 \pm 0.05$ \\
\hline
\end{tabular}

Note: The results were calculated and displayed as averages of four biological replicates.

\subsection{Growth of FAs8 on Glucose-Based Medium and Growth of GAs8 on Fructose-Based Medium}

The reduced lag phase was noticed when the evolved strain FAs8 was inoculated $(1 \%, v / v)$ into a fresh glucose-containing medium and the evolved strain GAs8 was inoculated into a fresh fructose-containing medium (Figure 3). This finding indicated that the evolved FAs8 can properly uptake and ferment glucose and vice versa, which confirms that the acquired mutation rather than a physiological adaptation promotes its rapid growth on monosaccharides, regardless of the type of hexose sugars. Furthermore, the biomass of GAs8 on fructose (GAs8-Fructose) was also higher than that of FAs8 on glucose (FAs8-Glucose), suggesting fructose is a more favored hexose sugar than glucose for the evolved $H$. thermocellum.

A

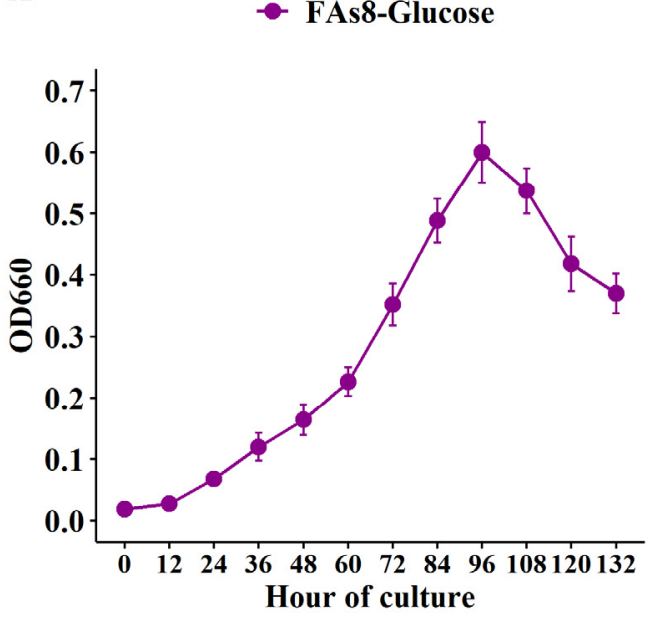

B

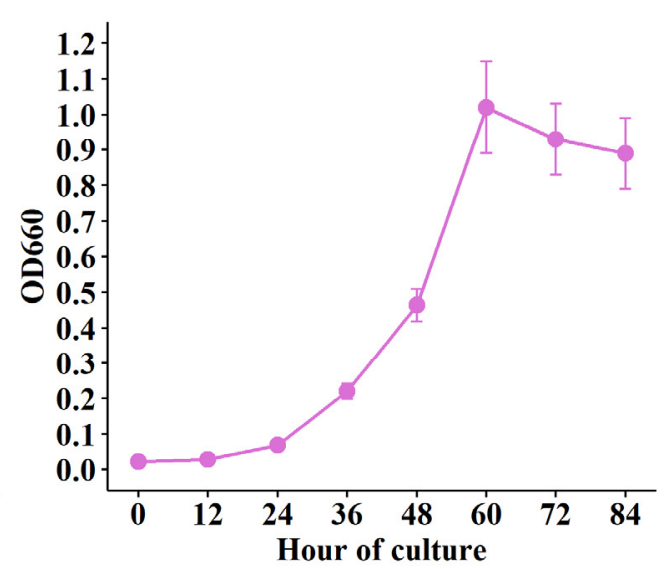

Figure 3. Growth pattern of the involved strains on different hexose sugars. (A) Growth pattern of FAs8 on fresh glucose medium. (B) Growth pattern of GAs8 on fresh fructose medium.

In addition, to determine whether the FAs8 and GAs8 strains still conserve the capacity for consuming cellobiose, the evolved strains were separately inoculated $(1 \%, v / v)$ into a fresh cellobiose-containing medium. As a result, these evolved strains can grow effectively on cellobiose, with a slightly higher specific growth rate for GAs8 $\left(0.069 \pm 0.003 \mathrm{~h}^{-1}\right)$ relative 
to FAs8 $\left(0.061 \pm 0.002 \mathrm{~h}^{-1}\right)$, in agreement with the results in Yayo et al. [38]. These results support an assumption that beneficial genetic changes are needed for better growth on monosaccharides, while the capability to ferment cellobiose was appropriately maintained in the evolved strains.

\subsection{Transcriptomic Profiling of CGs1, FAs1, GAs1 and Their Evolved Strains FAs8 and GAs8}

The expression patterns of cellulosomal genes in RNA-seq aided in confirming the results of enzyme activities. Our RNA-seq data showed that many carbohydrate-active enzyme (CAZyme)-encoding genes in GAs1 remained at low expression levels, while these genes exhibited higher expression levels in FAs1 (Table S3). To regulate the expression of cellulosomal genes in response to different substrates (i.e., cellulose, pectin, or xylan), H. thermocellum has an alternative sigma/antisigma (SigI/RsgI) factor system that works harmoniously via an external carbohydrate-sensing mechanism [3,4,51]. Although the carbon sources used in the present study were not specific carbohydrate targets of the SigI/RsgI system, several pairs of SigI/RsgI factors were differentially expressed (Table S3), which suggests potential roles in extracellular carbohydrate sensing of these antisigma factors in the presence of monosaccharides. In addition, given that the cellulosome could be inhibited by glucose [28] and cellobiose [59], latent regulators of non-cellulosomal enzymes might activate the expression of their regulons to hydrolyze any potential substrate in culture medium. Of the various non-cellulosomal genes known to date, we identified a dozen with differential expression in FAs1 and/or GAs1 (Table S3). In the study of Johnson et al. [29], the poor growth of $H$. thermocellum on fructose or sorbitol was accompanied by a significant increase (five- or six-fold higher) in the specific production of cellulase. This result was in accordance with Dror et al. [4,5], who found that the transcription of the exoglucanase gene celS (Cthe_2089), scaffolding protein gene cipA (Cthe_3077), two anchoring scaffoldin genes $\operatorname{lp} B$ (Cthe_3078) and orf2p (Cthe_3079) were affected by the growth rate rather than by the substrate itself. In other words, a slower growth rate of $H$. thermocellum should be associated with higher cellulase activity. In our RNA-seq data, celS, $\operatorname{cip} A, \operatorname{olp} B$, and orf2 $p$ were highly expressed in FAs1 and GAs1, except olpB was downregulated in GAs1 (Table S3). However, the production of specific cellulase was remarkably decreased when $H$. thermocellum cells were properly adapted to fructose [29], suggesting that carbon catabolite repression was responsible for the reduction of cellulase production. To further clarify this finding from a transcriptomic point of view, cell samples from FAs8 and GAs8 were collected for RNA-seq. The expression levels of key cellulosomal genes determined by RNA-seq and confirmed by RT-qPCR were dramatically decreased from FAs1 to FAs8, with CGs1 as the reference (Table S3), in agreement with the enzymatic analysis of Johnson et al. [29]. In their study, Johnson and colleagues [29] found that after several numbers of transfers, the cellulase yields of fructose-adapted cells were even lower than those of strains grown on cellobiose or glucose. On the other hand, numerous cellulosomal genes, such as celK (Cthe_0412), celB (Cthe_0536), celO (Cthe_0625), acetyl xylan esterase (Cthe_0798), celH (Cthe_1472), celS, glycoside hydrolase family 11 (Cthe_2167), celT (Cthe_2812), olpB, and orf2p, were upregulated in GAs8 relative to those in CGs1 and GAs1 (Table S3). This result suggests a de-repression of cellulase genes in the evolved GAs8 when glucose might be no longer an inhibitor of GAs8 cellulosomes. The list of primers used for RT-qPCR is shown in Table S4, and the correlation between RNA-seq and RT-qPCR is presented in Figures S1 and S2.

\subsection{EMP Pathway}

3.5.1. Genes Upstream of Phosphoenolpyruvate (PEP)

RNA-seq data in the present study demonstrated the dynamics of the transcriptome in the EMP pathway. This finding is in line with Xiong et al. [16], who found that the EMP pathway was the predominant glycolytic route in H. thermocellum. Many key glycolytic genes in the EMP pathway were highly upregulated in CGs1 compared to FAs1, FAs8, GAs1, and GAs8 (Figure 4). The $\log _{2}$ fold change of FAs1 and FAs8 relative to 
CGs1 and $\log _{2}$ fold change of GAs1 and GAs8 relative to CGs1 are presented as gene name (number1/number2 I number3/number4), respectively. As might be expected, the gene Cthe_0275 encoding a cellobiose phosphorylase (CBP, EC 2.4.1.20) that catalyzes the phosphorolysis of cellobiose into glucose 1-phosphate (Glc1P) and glucose (Glc) was upregulated in CGs1 relative to FAs1, GAs1 and the evolved FAs8 and GAs8. However, another CBP gene (Cthe_1221) was upregulated in FAs1 and GAs1. The role of this CBP gene in fructose metabolism and the possible existence of a regulator for its elevated level of expression remains to be studied. From Glc to 2-phosphoglycerate (2PGA), various genes involved in the conversion of sugar phosphate intermediates were found to be upregulated in CGs1 relative to FAs1, GAs1, FAs8 and GAs8. Specifically, Cthe_2938 encodes glucokinase (GCK, EC 2.7.1.2) which converts Glc to glucose 6-phosphate (Glc6P), and was upregulated in CGs1, in congruence with its elevated expression in carbon-repleted medium [22]. In a previous study, Patni and Alexander [32] found that the increase in GCK activity in GAs was proportional to the increase in the yield of cell mass. They argued that GCK was likely an inducible enzyme, as its synthesis could be induced by glucose, fructose, or mannose. Intriguingly, the activity of GCK increased in mannitol-grown cells after their suspension in glucose medium, suggesting a fundamental role of GCK in glucose metabolism. This finding, however, was in contrast with the expression pattern of Cthe_2938 in GAs8 as its activity was decreased with respect to that of CGs1. According to Yayo et al. [38], the inactivation of gene Cthe_0390, a Repressor-ORF-Kinase (ROK) transcriptional regulator, may help $H$. thermocellum to metabolize glucose and fructose better, thereby ameliorating growth rate and biomass formation. In our study, the decreased expression of Cthe_0390 in FAs8 and GAs8 was also recorded, suggesting a disruption to transcriptional process in this regulator.

The elevated expression of the GCK gene in CGs1 could be explained by the abundance of intracellular Glc formed from cellobiose, which is easily taken up from the cellobiose culture and then undergoes phosphorolytic cleavage by CBP to produce Glc1P and Glc. The high accumulation of sugar phosphate intermediates in FAs and GAs, which was first described by Nuchur et al. [31], was attributed to the accumulation rate of Fru6P being much greater in fructose medium than in cellobiose medium. This finding suggested that $H$. thermocellum metabolizes cellobiose much faster than hexose sugars. The accumulation of cellobiose, Glc6P, Fru6P, and 3PGA found in H. thermocellum growing under ethanol stress [21] suggests that a disrupted central carbon metabolism might severely hinder sugar fermentation. This study also indicated that the phosphofructokinase (PFK)- and phosphoglycerate mutase (PGAM)-encoding genes were downregulated under ethanol stress conditions, in agreement with what was observed for FAs1 and GAs1 under nutritional stress in the present study (Figure 4).

Other genes, such as Cthe_0217 encodes a glucose 6-phosphate isomerase (PGI, EC 5.3.1.9) responsible for Glc6P to fructose 6-phosphate (Fru6P) conversion, PPi-dependent 6-phosphofructokinase (PFK, EC 2.7.1.11) (Cthe_0347) and ATP-dependent PFK (EC 2.7.1.11) (Cthe_1261) catalyze the conversion of Fru6P to Fru16BP, and Cthe_0349 encodes a fructose1,6-bisphosphate aldolase (FBA, EC 4.1.2.13) regulating the conversion of fructose 1,6- bisphosphate (Fru16BP) to glyceraldehyde 3-phosphate (GAP), expressed upregulated activities in CGs1 as compared to FAs1, GAs1, FAs8, and GAs8. Gene expression patterns continued their upregulation trend in CGs1, as the three genes Cthe_0707, Cthe_0946 and Cthe_1292 encoding PGAM (EC 3.1.3.3) catalyze the conversion of 3-phosphoglycerate (3PGA) to 2-phosphoglycerate (2PGA) were found to be upregulated in CGs1 relative to FAs1, GAs1 and the evolved strains FAs8 and GAs8. Considering metabolite intermediates data from Nochur et al. [31], transcriptomic and metabolomic data from Yang et al. [21] and our RNA-seq together, we speculate that the low expression levels of EMP pathway genes in FAs1 and GAs1 led to less efficient monosaccharide metabolism, eventually causing the poor growth of $H$. thermocellum. 


\section{Cellobiose, Fructose, Glucose}

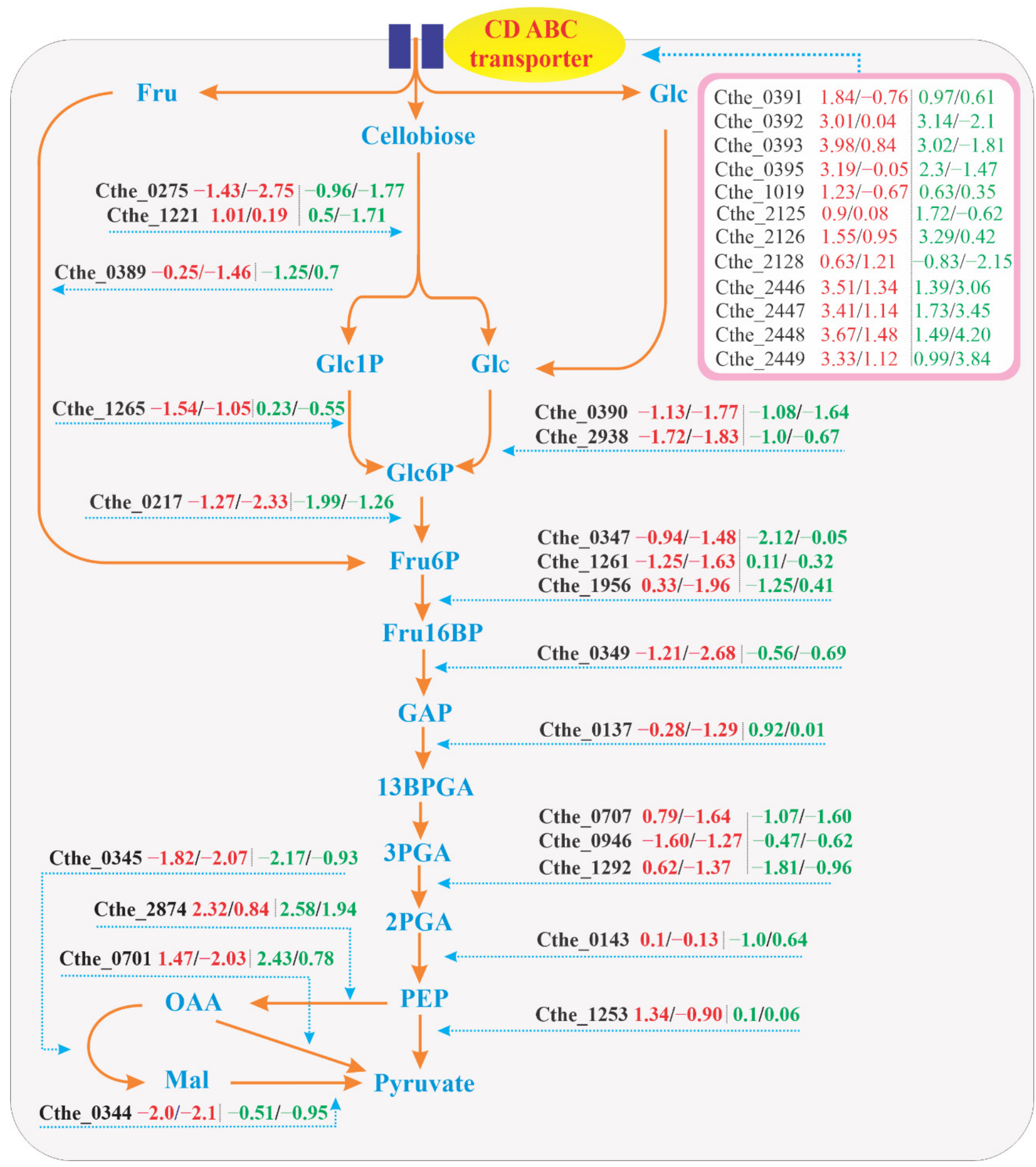

Figure 4. Diagram of the genes involved in EMP pathway in FAs1, FAs8, GAs1, and GAs8, relative to CGs1.

Regarding the involved strain GAs8, various key genes including Cthe_0347, Cthe_1956, Cthe_1292, Cthe_0143, and Cthe_0217 were found to have increased their mRNA expression to a certain extent when compared to the parent strain, GAs1. In contrast, in FAs8, only two genes (Cthe_1265 and Cthe_0946) exhibited a slightly upregulated pattern relative to FAs1. Therefore, transcriptomic profile alone cannot adequately explain the acquired phenotype 
of FAs8. Additional information from genome resequencing with genetic mutations may help to elucidate the phenotype of FAs8 better.

\subsubsection{Genes Downstream of PEP}

The malate shunt is responsible for catalyzing the indirect conversion of PEP to pyruvate via malate. The absence of an annotated pyruvate kinase sequence in the H. thermocellum genome, no pyruvate kinase (PYK, EC 2.7.1.40) enzyme activity detected in cell extracts, and pyruvate phosphate dikinase (PPDK, EC 2.7.9.1) is unlikely to be crucial for the conversion of pyruvate from PEP $[60,61]$, leading to an assumption that pyruvate formation could be proceeded predominantly via a malate shunt [62]. Moreover, metabolic flux ratio (METAFoR) analysis also suggested that the malate shunt is the primary pathway which directs the carbon flux from PEP to pyruvate [61]. In our RNA-seq, two of three genes involved in the malate shunt, such as $\mathrm{NADP}^{+}$-dependent malic enzyme (ME) (Cthe_0344) and NADH-dependent malate dehydrogenase (MDH) (Cthe_0345), demonstrated elevated expression levels in CGs1, whereas the gene Cthe_2874 encoding phosphoenolpyruvate carboxykinase (GTP), which is responsible for the conversion of PEP to oxaloacetate (OAA), maintained an upregulated level in FAs1, GAs1, FAs8, and GAs8. Furthermore, as ITP can substitute for GTP in the carboxylase reaction, the upregulation of the inosine 5-monophosphate dehydrogenase-encoding gene (Cthe_0681) in CGs1, which is an enzyme involved in the synthesis of guanine nucleotides, further supports the idea that the malate shunt is the main glycolytic route for producing pyruvate in H. thermocellum [19]. Alternatively, OAA can be directly decarboxylated into pyruvate using the membrane-bound enzyme oxaloacetate decarboxylase (ODC, EC 4.1.1.3). Although previous studies $[23,38]$ provided evidence of the moderate expression of the ODC gene Clo1313_1523 ( C Cthe_0701 in ATCC 27405), our RNA-seq data revealed that the gene Cthe_0701 [1.47/-2.03 | 2.43/0.78] had higher expression in FAs1 and GAs1, similar to its expression pattern in planktonic cells, a common cell fraction of bacterial population in carbon-depleted medium [22]. Although Olson et al. [62] could not detect ODC activity in their study, we assume that the inconsistency may be due to the different strains of H. thermocellum used in these works (e.g., Olson et al. used H. thermocellum DSM 1313, whereas we used H. thermocellum ATCC 27405).

Gene IDs and corresponding $\log _{2}$ fold change (FC) values (number 1/number 2/number $3 /$ number 4 ) are displayed in the box. Text in red represents expression levels of FAs1 and FAs8, respectively, and text in green displays expression levels of GAs1 and GAs8, respectively. Nomenclature of metabolites is as follows: 2PGA: 2-phosphoglycerate; 3PGA: 3-phosphoglycerate; 13BPGA: 1,3-bisphosphoglycerate; CD ABC transporter: Cellodextrin ATP-binding cassette transporter; Fru: Fructose; Glc: Glucose; CBP: Cellobiose phosphorylase; Fru6P: Fructose 6-phosphate; Fru16BP: Fructose 1,6- bisphosphate; FBA: Fructose-bisphosphate aldolase; GA3P: Glyceraldehyde 3-phosphate; Glc: Glucose; GAP: Glyceraldehyde 3-phosphate; Glc1P: Glucose 1-phosphate; Glc6P: Glucose 6-phosphate; GCK: Glucokinase; Mal: Malate; MDH: Malate dehydrogenase; ME: Malic enzyme; OAA: Oxaloacetate; PGI: Glucose-6phosphate isomerase; PEP: Phosphoenolpyruvate; PFK: Phosphofructokinase; PGAM: Phosphoglycerate mutase; PPDK: Pyruvate phosphate dikinase; PYK: Pyruvate kinase; PEP: Phosphoenolpyruvate; Pi: Inorganic phosphate.

\subsection{EMP Pathway}

Among the five operons encoding cello-oligosaccharide $\mathrm{ABC}$ transport proteins identified by Nataf et al. [63], three operons, $\mathrm{CbpA}, \mathrm{CbpB}$, and $\mathrm{CbpD}$, were experimentally proven to be specific to cellodextrins of different lengths (G2-G5). Therefore, it is not expected that these sugar transporters would exhibit high levels of expression during growth on monosaccharides. Due to the absence of cellodextrins in the growth medium, Rydzak et al. [20] could not detect proteins expressed from either the CbpC (Cthe_2125-2128) or CbpD (Cthe_2446-2449) operons in H. thermocellum cells. However, high expression levels of these sugar transporter-encoding genes were found during growth on fructose and glu- 
cose in this present study. The mRNA expression levels of ATP-binding protein $n b d A$ (Cthe_0391), inner membrane translocator $m s d A$ (Cthe_0392), and ribose ABC transporter $\operatorname{cbp} A$ (Cthe_0393) were significantly upregulated in FAs1 and GAs1 (Figure 4). Additionally, the transmembrane sugar transport protein msdB1 (Cthe_1019) in the CbpB operon also exhibited an upregulated expression level. As CbpC transport proteins can bind to glucose [63], it was not surprising that two of four genes in the CbpC operon, namely the binding protein-dependent transport system $m s d C 1$ (Cthe_2125) and permease component $m s d C 2$ (Cthe_2126), were highly expressed in GAs1 and, to a lesser extent, in FAs1. Four genes of the CbpD operon (Cthe_2446-2449), such as ribose ABC transporter $c b p D$, ATP-binding protein $n b d D$, inner-membrane translocator $m s d D$, and phosphoglycerate mutase $p g m D$, were upregulated in FAs1 and GAs1. In the study of Rangel and coworkers [64] where xylose was used as the sole carbon source, two sugar transporter genes $c b p C$ (Cthe_2128) and $c b p D$ (Cthe_2446) were found to be upregulated. Interestingly, in our study, after numerous generations, these genes of the $\mathrm{CbpD}$ operon still maintained their highly expressed activities in FAs8 and GAs8, thus indicating their fundamental importance in hexose sugars transport. In contrast, after adaptation to fructose was well established, the expression levels of genes encoding sugar transporters, except for the CbpD operon, significantly decreased in FAs8 and GAs8 (Figure 4).

\subsection{Energy Generation and Redox Balance}

With regards to energy production, while all F-type ATPase genes (Cthe_2602-2609) of FAs1 and GAs1 were downregulated, some V-type ATPase genes were upregulated in GAs1 (Cthe_2266-2269) or in both FAs1 and GAs1 (Cthe_2262-2265). Cellular redox imbalance under certain conditions may cause incomplete substrate utilization and slow growth of bacteria. Redox metabolism of $H$. thermocellum is complex, with multiple reactions that shuttle electrons between reduced ferredoxin (Fd), NADH, and NADPH. These reactions use different enzyme complexes, such as reduced Fd:NAD $(\mathrm{P})$ oxidoreductases and several $\mathrm{Fe}-\mathrm{Fe}$ and Ni-Fe hydrogenases that are activated by hydrogenase maturase (HydG) [61]. Therefore, $H$. thermocellum produces molecular hydrogen via a hydrogenase-mediated pathway to dispose of the excess reductants generated during carbohydrate catabolism [10]. Hydrogen production has important roles in regenerating oxidized Fd and NADH as it is used as the final electron acceptor for pyruvate:ferredoxin oxidoreductase (PFOR) during the conversion of pyruvate to acetyl-CoA [65]. Sander et al. [5] reported that four redox-active pathways, namely sulfate transport and metabolism, ammonia assimilation, porphyrin biosynthesis, and [Ni-Fe] Fd-dependent hydrogenase, in H. thermocellum DSM 1313 showed decreased transcription after the addition of methyl viologen, a redox-active chemical, to balance cellular redox. In the present study, FAs1 exhibited the upregulated expression in [Ni-Fe] hydrogenase (Cthe_3013, Cthe_3016, Cthe_3018, Cthe_3019, Cthe_3020, Cthe_3022, Cthe_3023, and Cthe_3024), ammonia assimilation-related genes (Cthe_0197-0199) and porphyrin biosynthesis (Cthe_2525), but several gene involved in sulfate metabolism (Cthe_2531-2534, Cthe_2536-2538) were downregulated (Table S5). On the other hand, GAs1 had highly expressed genes in both [Ni-Fe] and [Fe-Fe] hydrogenases (i.e., Cthe_3013, Cthe_3014, Cthe_3018, Cthe_3020, Cthe_0428, Cthe_0429, Cthe_0430), ammonia assimilation genes (Cthe_0197-0199), porphyrin biosynthesis gene (Cthe_2525, Cthe_2527, Cthe_2528, Cthe_2529), and sulfate transport (Cthe_2533). The results suggest that FAs1 and GAs1 did not suffer much from redox imbalance as hydrogen production was favorably maintained for cell redox homeostasis. Transcriptomic data of FAs8 and GAs8 showed that genes related to ammonia assimilation (Cthe_0197-0199) still sustained their elevated expression relative to CGs1. However, most genes involved in [Ni-Fe] hydrogenase, porphyrin biosynthesis, and sulfate metabolism in FAs8 and GAs8 were downregulated in comparison with their respective FAs1 and GAs1. The downregulation pattern may indicate that the evolved phenotypes do not need a large amount of hydrogen to function as an electron acceptor in rebalancing the cells redox state, however, further investigation is needed to thoroughly clarify this phenomenon. 


\subsection{Other DEGs in Different Categories}

Under conditions offering only poorly fermentable substrates, the bacterium needs to increase its motility and signal transduction systems to seek a better carbon source in the environment. This explains the greater numbers of DEGs in category $\mathrm{N}$ and category $\mathrm{T}$ in FAs1 and GAs1 relative to CGs1 (Tables S6-S8). However, this upregulated pattern of genes in category $\mathrm{N}$ was altered in FAs8 and GAs8 when the adaptation to hexoses was well established. $\mathrm{NAD}^{+}$and $\mathrm{NADP}^{+}$are important cofactors that are usually involved in catabolism and anabolism, respectively [22]. In FAs1 and GAs1, the four genes responsible for NAD ${ }^{+}$biosynthesis via L-aspartate (Cthe_0325, Cthe_2355, Cthe_2356, Cthe_1241) and one gene ATP-NAD kinase (Cthe_0816) for the conversion of $\mathrm{NAD}^{+}$to $\mathrm{NADP}^{+}$were downregulated relative to CGs1. This supports the observation that CGs1 had a higher rate of carbohydrate assimilation and faster cell growth.

Regarding the antioxidant response, a rubredoxin-type $\mathrm{Fe}(\mathrm{Cys}) 4$ protein gene (Cthe_0063) was found to be upregulated in GAs1. Another rubredoxin protein gene (Cthe_2164) had upregulated expression in both FAs1 and GAs1. This class of protein is strictly found in anaerobic bacteria and archaea where it plays roles in the reduction of oxygen. Other antioxidant protein FAD-dependent oxidoreductase gene Cthe_0200 exhibited elevated expression in GAs1 and FAs8, whereas another FAD-dependent oxidoreductase gene (Cthe_0560) was upregulated in both. Additionally, a peroxiredoxin gene (Cthe_1965) was upregulated in GAs1 and GAs8. In general, just some antioxidant-related genes were statistically significantly expressed in carbon-challenged medium. Other downregulated genes such as glutathione S-transferase N-terminal domain (Cthe_0235) were found in FAs1, GAs1, FAs8, and GAs8, thioredoxin (Cthe_0360) in FAs1 and FAs8, peroxiredoxin (Cthe_1465) in FAs1, GAs1, and FAs8, and FAD-dependent pyridine nucleotide-disulphide oxidoreductase (Cthe_1164) in FAs8.

In general, there was no significant difference between quantities of DEGs in the parent strains FAs1 and GAs1 and in the evolved FAs8 and GAs8. However, the ratio of upregulated genes to downregulated genes was tremendously decreased from the parent strains to the evolved strains. We assume that in a growth medium with hexose sugar as a sole carbon source and energy, FAs1 and GAs1 cells needed to exploit all necessary pathways to produce energy, transport organic and inorganic elements, induce signal transmission, and accelerate transcriptional and translational processes to cope with the harsh conditions. This explains why numerous genes in all categories were upregulated in comparison with CGs1, except for genes involved in EMP pathway. After the useful mutations for growth in fructose- and glucose-based medium had been well established, their expression levels were repressed to save energy for other essential physio-biochemical aspects. Consequently, the evolved strains achieved greater biomass, higher growth rate, and higher ethanol yield. Furthermore, the significant upregulation of urease (Cthe_1812-18) and urea ABC transport (Cthe_1819-23) genes in FAs8 was recorded, whereas most nitrogen assimilation genes in GAs8 were downregulated, except for Cthe_1823 (Table S9), which may explain the higher biomass of FAs8 as compared to that of GAs8.

\subsection{Genomic Analysis}

To overcome environmental stress, the mutation rate in the bacterial genome in the late phase of the adaptation period increases to allow the development of an evolved phenotype [36]. In the present study, which required the bacteria to adapt quickly to harsh nutritional conditions, various mutations were detected in H. thermocellum using genomic resequencing. In the study by Yayo et al. [38] H. thermocellum DSM 1313 was cultured in the carbon-limited chemostats with an increasing glucose or fructose concentration and decreasing cellobiose concentration strategy, in our study, we cultured H. thermocellum ATCC 27,405 in batch culture with sole fructose-, glucose-, or cellobiose-supplemented medium from the beginning of culture. The addition of $100 \%$ less-preferred hexose sugars to growth medium created a harsh condition and nutritional stress for $H$. thermocellum. Consequently, the only way for the bacterium to survive and thrive was to quickly adapt to new carbon sources by mutation acquisition. 
In the genomes of the evolved strains FAs8 and GAs8, we found an insertion or deletion (indel) mutation in the $\mathrm{MDH}$ (Cthe_0345) gene, an insertion/deletion (indel) \& stop-gain mutation in the GCK (Cthe_0390) gene and a nonsynonymous (non-syn) mutation in the CBP (Cthe_1221) gene (Table S10). While the deletion of a putative ROK family transcriptional regulator Clo1313_1831 ( Cthe_0390 in strain ATCC 27405) facilitated immediate growth on glucose and a reduced lag phase on fructose [38], in our study, an insertion of $\mathrm{T}$ at the 49/1215 position caused a frameshift and stop gain in the evolved strains FAs8 and GAs8. This type of mutation may lead to a severe disruption in the transcriptional process of the Cthe_0390 gene, thus accounting for its low expression level. We may propose that this mutation also leads to the reduced lag phase on fructose and glucose, as observed by Yayo et al. [38].

We also found various mutations in sugar transporter genes of the evolved strains. Specifically, an indel mutation (deletion of GG at position 19/1050) was observed in the $m s d A$ gene (Cthe_0392) of FAs8 and GAs8. Both indel and stop-gain events occurred in the $n b d A$ gene (Cthe_0391) of FAs8. The $c b p B$ gene (Cthe_1020) in GAs8 had a non-syn mutation (Ala was replaced by $\mathrm{Val}^{92}$ ). The gene encoding sugar-binding periplasmic protein $c b p C$ (Cthe_2128) of FAs8 and GAs8 had a non-syn substitution (Gln was altered by Glu ${ }^{355}$ ). Since the sugar-binding protein $\mathrm{CbpC}$ operon could bind glucose and cellobiose, we suspect that this mutation might improve the binding affinity of this protein to glucose and fructose. We also found a stop-gain mutation $\left(G \ln 148^{*}\right)$ in the $n b d D$ gene (Cthe_2447) of FAs8. This type of mutation may abolish the function of the $n b d D$ gene, however, other transporter(s) may compensate for its role, as observed in the study of Rangel et al. [64]. Since these genes belong to the $\mathrm{CbpA}, \mathrm{CbpB}, \mathrm{CbpC}$, and $\mathrm{CbpD}$ operons, which are responsible for polysaccharide G2-G5 transport, the mutations found in the evolved strains might improve the transport of Fru or Glc into the cells by altering substrate specificity. A non-syn SNP (G538A) may disrupt the gene function of the canonical master sporulation regulator spo0A (Cthe_3087), which may result in faster growth of the evolved strains FAs8 and GAs8. The mutation of $s p o 0 A$ was consistent with its downregulated regulation in FAs8 and GAs8. Our finding was corroborated by the study of Linville and coworkers [8,13] as a stop codon occurred in the coding sequence (CDS) of Clo1313_0637 ( Cthe_3087) of a mutant strain accounted for a better tolerance to and a faster growth in Populus hydrolysate-containing medium.

Regarding cellulosomal genes, we found a synonymous (syn) mutation in olpB (Cthe_3078) gene in the evolved FAs8, as A was replaced by $\mathrm{G}^{5403}$, which may cause a reduction in gene expression. Furthermore, a syn mutation (Ala ${ }^{313} \mathrm{Val}$ ) was acquired in $h t p G$ (Cthe_0550) gene of FAs8 and GAs8. The htpG gene was found to be upregulated in all stress treatments, including ethanol stress, furfural, or heat shock, which points out the important role of this gene in stress tolerance [11]. Although this is just a syn mutation, its importance should be noted, as the ecological adaptation of bacteria to a new environment can also occur through synonymous changes, as they affect the nature of mRNA/tRNA interactions [66]. In addition, codon selection is common in both prokaryotes and eukaryotes and fundamentally influences the synthesis of a particular polypeptide and/or the accuracy of translation [67]. UvrABC excinuclease plays an important role in bacterial nucleotide excision repair [68]. In the present study, a non-syn mutation was found in the open reading frame of the excinuclease ABC subunit uvrB gene (Cthe_0309), where amino acid His was replaced by Arg at position 402 (Table S10). An indel mutation (deletion of Ala at position 192 causes a frameshift variant) occurred in the deoR transcriptional regulator (Cthe_2441) of the evolved FAs8. In E. coli, deoT, a DeoR-type transcriptional regulator, represses the expression of genes involved in a variety of metabolic pathways related to maltose, fatty acid $\beta$-oxidation and peptide degradation [69]. In FAs 8 and GAs8, araC (Cthe_3164) acquired a stop mutation at position 227 (this gene is homologous to the araC gene in $E$. coli, with $22.67 \%$ identity). In $E$. coli, araC functions as a transcription factor regulating the expression of several genes involved in the transport and metabolism of 
L-arabinose [70], and regulators of the AraC/XylS family are involved in the metabolism of certain carbon sources [71].

It is worthy to note that, although the isolation of individual evolved strains is necessary for identifying causative mutations and for further genetic engineering [37], in our pangenome analysis, most sequencing reads associated with the mutated genes had SNVs, which confirm that all bacterial cells in the evolved populations already acquired mutations which are beneficial to hexoses-adapted phenotypes.

\section{Conclusions}

In summary, the advances in NGS and RNA-seq technologies allowed us to gain insight into the genetic basis and dynamics of adaptation in bacterial populations. RNA-seq showed large changes in core metabolic pathways during growth on different carbon sources, and the most significant transcriptional level differences were related to the EMP pathway genes, ABC sugar transporters and CAZymes. On the other hand, genomic analysis pointed out that mutations in various genes related to carbon transport (ABC transporters) and carbon metabolism occurred in the genomes of the evolved FAs8 and GAs8 strains. These genes could be good candidates for further metabolic engineering approaches to improve biofuel production using this bacterium. This study also has enhanced our understanding of the physiology, metabolism, and nutritional adaptation of H. thermocellum.

Supplementary Materials: The following are available online at https:/ /www.mdpi.com/article/10 .3390 / microorganisms9071445/s1, Figure S1: Correlation between RT-qPCR and RNA-seq results in FAs1, GAs1, and CGs1. Figure S2: Correlation between RT-qPCR and RNA-seq results in FAs8, GAs8, and CGs1. Table S1: Raw counts of RNA-seq (CGs1, FAs1, GAs1). Table S2: Raw counts of RNA-seq (CGs1, FAs8, GAs8). Table S3: List of cellulosomal, noncellulosomal, sigma-antisigma factor genes. Table S4: Primers list for RT-qPCR. Table S5: List of four redox active pathways-related genes, Table S6: Number of DEGs in clusters of orthologous groups. Table S7: DEGs of FAs1, FAs8 vs. CGs1 in different COGs. Table S8: DEGs of GAs1, GAs8 vs. CGs1 in different COGs. Table S9: List of nitrogen assimilation and metabolism. Table S10: List of mutant genes in the evolved strains FAs8 and GAs8.

Author Contributions: Conceptualization, D.M.H.-T. and C.-C.H.; Methodology and Investigation, D.M.H.-T., S.-C.L. and C.-C.H.; Software, D.M.H.-T. and T.T.M.N.; Data Curation, D.M.H.-T., T.T.M.N. and C.-C.H.; Writing-Original Draft Preparation, D.M.H.-T., S.-C.L. and C.-C.H.; Writing-Review and Editing, D.M.H.-T., T.T.M.N., S.-C.L. and C.-C.H.; Supervision, S.-C.L. and C.-C.H.; Funding Acquisition, S.-C.L. and C.-C.H. All authors have read and agreed to the published version of the manuscript.

Funding: The study was supported by the Ministry of Science and Technology (104-2621-M-005003-MY3 and 107-2621-M-005-007-MY3 to C.-C.H. and 107-2621-M-005-001 to S.-C.L.)

Data Availability Statement: The RNA-seq raw counts could be found in the supplemental files of this paper.

Acknowledgments: The authors would like to deeply acknowledge John Nghiem, Biosystems Engineering Program, Department of Environmental Engineering and Earth Sciences, Clemson University, South Carolina, USA for his thorough English editing, valuable comments, and constructive suggestions.

Conflicts of Interest: The authors declare no conflict of interest.

\begin{tabular}{|c|c|}
\hline \multicolumn{2}{|c|}{ Abbreviations } \\
\hline 2PGA & 2-phosphoglycerate \\
\hline 3PGA & 3-phosphoglycerate \\
\hline 13BPGA & 1,3-bisphosphoglycerate \\
\hline A & Adenine \\
\hline ALE & Adaptive laboratory evolution \\
\hline
\end{tabular}




\begin{tabular}{ll} 
BSA & Bovine serum albumin \\
CAZymes & Carbohydrate-active enzymes \\
CBM & Carbohydrate-binding module \\
CBP & Cellobiose phosphorylase \\
CDS & Coding sequence \\
CGs & Cellobiose-grown cells \\
CMC & Carboxymethylcellulose \\
DE & Differential expression \\
DEGs & Differentially expressed genes \\
FAs & Fructose-adapted cells \\
Fd & Ferredoxin \\
Fru & Fructose \\
Fru6P & Fructose 6-phosphate \\
Fru16BP & Fructose 1,6-biphosphate \\
FBA & Fructose-bisphosphate aldolase \\
G & Guanine \\
Glc & Glucose \\
GAP & Glyceraldehyde 3-phosphate \\
GAs & Glucose-adapted cells \\
Glc1P & Glucose 1-phosphate \\
Glc6P & Glucose 6-phosphate \\
GCK & Glucokinase \\
GH & Glycoside hydrolase \\
GHnc & Glycoside hydrolase family “Non classified” \\
GA3P & Glyceraldehyde 3-phosphate \\
GTP & Guanosine-5'-triphosphate \\
indel & Insertion/Deletion \\
ITP & Inosine triphosphate \\
Mal & Malate \\
MDH & Malate dehydrogenase \\
ME & Malic enzyme \\
nbdA & ATP-binding protein \\
NGS & Next-generation sequencing \\
non-syn & Nonsynonymous \\
OAA & Oxaloacetate \\
ODC & Oxaloacetate decarboxylase \\
PGI & Glucose-6-phosphate isomerase \\
PEP & Phosphoenolpyruvate \\
PFK & Phosphofructokinase \\
PGAM & Phosphoglycerate mutase \\
PPDK & Pyruvate phosphate dikinase \\
PYK & Pyruvate kinase \\
& Single nucleotide variations \\
synonymous \\
\hline fH &
\end{tabular}

\section{References}

1. Dror, T.W.; Morag, E.; Rolider, A.; Bayer, E.A.; Lamed, R.; Shoham, Y. Regulation of the Cellulosomal celS (cel48A) Gene of Clostridium thermocellum Is Growth Rate Dependent. J. Bacteriol. 2003, 185, 3042-3048. [CrossRef] [PubMed]

2. Dror, T.W.; Rolider, A.; Bayer, E.A.; Lamed, R.; Shoham, Y. Regulation of Expression of Scaffoldin-Related Genes in Clostridium thermocellum. J. Bacteriol. 2003, 185, 5109-5116. [CrossRef] [PubMed]

3. Kahel-Raifer, H.; Jindou, S.; Bahari, L.; Nataf, Y.; Shoham, Y.; Bayer, E.A.; Borovok, I.; Lamed, R. The unique set of putative membrane-associated anti- $\sigma$ factors in Clostridium thermocellum suggests a novel extracellular carbohydrate-sensing mechanism involved in gene regulation. FEMS Microbiol. Lett. 2010, 308, 84-93. [CrossRef] [PubMed]

4. Bahari, L.; Gilad, Y.; Borovok, I.; Kahel-Raifer, H.; Dassa, B.; Nataf, Y.; Shoham, Y.; Lamed, R.; Bayer, E.A. Glycoside hydrolases as components of putative carbohydrate biosensor proteins in Clostridium thermocellum. J. Ind. Microbiol. Biotechnol. 2011, 38, 825-832. [CrossRef] [PubMed]

5. Sander, K.; Wilson, C.M.; Rodriguez, M.; Klingeman, D.M.; Rydzak, T.; Davison, B.H.; Brown, S.D. Clostridium thermocellum DSM 1313 transcriptional responses to redox perturbation. Biotechnol. Biofuels 2015, 8, 1-14. [CrossRef] 
6. Choi, J.; Klingeman, D.M.; Brown, S.D.; Cox, C.D. The LacI family protein GlyR3 co-regulates the celC operon and manB in Clostridium thermocellum. Biotechnol. Biofuels 2017, 10, 163. [CrossRef]

7. De Ora, L.O.; Lamed, R.; Liu, Y.-J.; Xu, J.; Cui, Q.; Feng, Y.; Shoham, Y.; Bayer, E.A.; Muñoz-Gutiérrez, I. Regulation of biomass degradation by alternative $\sigma$ factors in cellulolytic clostridia. Sci. Rep. 2018, 8, 1-11. [CrossRef]

8. Linville, J.; Rodriguez, M., Jr.; Land, M.; Syed, M.; Engle, N.; Tschaplinski, T.; Mielenz, J.; Cox, C. Industrial Robustness: Understanding the Mechanism of Tolerance for the Populus Hydrolysate-Tolerant Mutant Strain of Clostridium thermocellum. PLoS ONE 2013, 8, e78829. [CrossRef] [PubMed]

9. Holwerda, E.K.; Olson, D.G.; Ruppertsberger, N.M.; Stevenson, D.M.; Murphy, S.; Maloney, M.I.; Lanahan, A.A.; Amador-Noguez, D.; Lynd, L.R. Metabolic and evolutionary responses of Clostridium thermocellum to genetic interventions aimed at improving ethanol production. Biotechnol. Biofuels 2020, 13, 1-20. [CrossRef]

10. Raman, B.; McKeown, C.; Rodriguez, M., Jr.; Brown, S.; Mielenz, J. Transcriptomic Analysis of Clostridium thermocellum ATCC 27405 Cellulose Fermentation. BMC Microbiol. 2011, 11. Available online: www.biomedcentral.com/1471-2180/11/134 (accessed on 15 May 2021). [CrossRef]

11. Wilson, C.; Yang, S.; Rodriguez, M., Jr.; Ma, Q.; Johnson, C.; Dice, L.; Xu, Y.; Brown, S. Clostridium thermocellum Transcriptomic Profiles after Exposure to Furfural or Heat Stress. Biotechnol. Biofuels 2013, 6. Available online: www.biotechnologyforbiofuels. com/content/6/1/131 (accessed on 20 May 2020). [CrossRef]

12. Wilson, C.; Rodriquez, M., Jr.; Johnson, C.; Martin, S.; Chu, T.; Wolfinger, R.; Hauser, L.; Land, M.; Klingeman, D.; Syed, M.; et al. Global Transcriptome Analysis of Clostridium thermocellum ATCC 27405 during Growth on Dilute Acid Pretreated Populus and Switchgrass. Biotechnol. Biofuels 2013, 6, 1-18. Available online: www.biotechnologyforbiofuels.com/content/6/1/179 (accessed on 10 June 2021). [CrossRef] [PubMed]

13. Linville, J.; Rodriguez, M., Jr.; Brown, S.; Mielenz, J.; Cox, C. Transcriptomic Analysis of Clostridium thermocellum Populus Hydrolysate-Tolerant Mutant Strain Shows Increased Cellular Efficiency in Response to Populus Hydrolysate Compared to the Wild Type Strain. BMC Microbiol. 2014, 14, 1-17. Available online: www.biomedcentral.com/1471-2180/14/215 (accessed on 20 May 2020). [CrossRef]

14. Wei, H.; Fu, Y.; Magnusson, L.; Baker, J.O.; Maness, P.-C.; Xu, Q.; Yang, S.; Bowersox, A.; Bogorad, I.; Wang, W.; et al. Comparison of transcriptional profiles of Clostridium thermocellum grown on cellobiose and pretreated yellow poplar using RNA-Seq. Front. Microbiol. 2014, 5, 142. [CrossRef] [PubMed]

15. Tian, L.; Perot, S.J.; Stevenson, D.; Jacobson, T.; Lanahan, A.A.; Amador-Noguez, D.; Olson, D.G.; Lynd, L.R. Metabolome analysis reveals a role for glyceraldehyde 3-phosphate dehydrogenase in the inhibition of C. thermocellum by ethanol. Biotechnol. Biofuels 2017, 10, 1-11. [CrossRef]

16. Xiong, W.; Lo, J.; Chou, K.J.; Wu, C.; Magnusson, L.; Dong, T.; Maness, P. Isotope-Assisted Metabolite Analysis Sheds Light on Central Carbon Metabolism of a Model Cellulolytic Bacterium Clostridium thermocellum. Front. Microbiol. 2018, 9, 1947. [CrossRef]

17. Gold, N.D.; Martin, V.J.J. Global View of the Clostridium thermocellum Cellulosome Revealed by Quantitative Proteomic Analysis. J. Bacteriol. 2007, 189, 6787-6795. [CrossRef]

18. Raman, B.; Pan, C.; Hurst, G.; Rodriguez, M., Jr.; McKeown, C.; Lankford, P.; Samatova, N.; Mielenz, J. Impact of Pretreated Switchgrass and Biomass Carbohydrates on Clostridium thermocellum ATCC 27405 Cellulosome Composition: A Quantitative Proteomic Analysis. PLoS ONE 2009, 4, e5271. [CrossRef] [PubMed]

19. Burton, E.; Martin, V.J. Proteomic analysis of Clostridium thermocellum ATCC 27405 reveals the upregulation of an alternative transhydrogenase-malate pathway and nitrogen assimilation in cells grown on cellulose. Can. J. Microbiol. 2012, 58, 1378-1388. [CrossRef]

20. Rydzak, T.; McQueen, P.D.; Krokhin, O.V.; Spicer, V.; Ezzati, P.; Dwivedi, R.C.; Shamshurin, D.; Levin, D.B.; Wilkins, J.A.; Sparling, R. Proteomic analysis of Clostridium thermocellum core metabolism: Relative protein expression profiles and growth phase-dependent changes in protein expression. BMC Microbiol. 2012, 12, 214. [CrossRef]

21. Yang, S.; Giannone, R.J.; Dice, L.; Yang, Z.K.; Engle, N.L.; Tschaplinski, T.J.; Hettich, R.L.; Brown, S.D. Clostridium thermocellum ATCC27405 transcriptomic, metabolomic and proteomic profiles after ethanol stress. BMC Genom. 2012, $13,336$. [CrossRef] [PubMed]

22. Dumitrache, A.; Klingeman, D.M.; Natzke, J.; Rodriguez, M., Jr.; Giannone, R.J.; Hettich, R.L.; Davison, B.H.; Brown, S.D. Specialized activities and expression differences for Clostridium thermocellum biofilm and planktonic cells. Sci. Rep. 2017, 7, 1-14. [CrossRef] [PubMed]

23. Poudel, S.; Giannone, R.J.; Rodriguez, M.; Raman, B.; Martin, M.Z.; Engle, N.L.; Mielenz, J.R.; Nookaew, I.; Brown, S.D.; Tschaplinski, T.J.; et al. Integrated omics analyses reveal the details of metabolic adaptation of Clostridium thermocellum to lignocellulose-derived growth inhibitors released during the deconstruction of switchgrass. Biotechnol. Biofuels 2017, 10, 14. [CrossRef] [PubMed]

24. Whitham, J.; Moon, J.-W.; Rodriguez, M.; Engle, N.L.; Klingeman, D.M.; Rydzak, T.; Abel, M.M.; Tschaplinski, T.J.; Guss, A.M.; Brown, S.D. Clostridium thermocellum LL1210 pH homeostasis mechanisms informed by transcriptomics and metabolomics. Biotechnol. Biofuels 2018, 11, 98. [CrossRef] [PubMed]

25. Stevenson, D.M.; Weimer, P.J. Expression of 17 Genes in Clostridium thermocellum ATCC 27405 during Fermentation of Cellulose or Cellobiose in Continuous Culture. Appl. Environ. Microbiol. 2005, 71, 4672-4678. [CrossRef] [PubMed] 
26. Zhang, Y.; Lynd, L. Regulation of Cellulase Synthesis in Batch and Continuous Cultures of Clostridium thermocellum. J. Bacteriol. 2005, 187, 99-106. [CrossRef] [PubMed]

27. Prawitwong, P.; Waeonukul, R.; Tachaapaikoon, C.; Pason, P.; Ratanakhanokchai, K.; Deng, L.; Sermsathanaswadi, J.; Septiningrum, K.; Mori, Y.; Kosugi, A. Direct glucose production from lignocellulose using Clostridium thermocellum cultures supplemented with a thermostable $\beta$-glucosidase. Biotechnol. Biofuels 2013, 6, 184. [CrossRef]

28. Zhang, P.; Wang, B.; Xiao, Q.; Wu, S. A kinetics modeling study on the inhibition of glucose on cellulosome of Clostridium thermocellum. Bioresour. Technol. 2015, 190, 36-43. [CrossRef]

29. Johnson, E.A.; Bouchot, F.; Demain, A.L. Regulation of Cellulase Formation in Clostridium thermocellum. Microbiology 1985, 131, 2303-2308. [CrossRef]

30. Nochur, S.; Roberts, M.; Demain, A. Mutation of Clostridium thermocellum in the Presence of Certain Carbon Sources. FEMS Microbiol. Lett. 1990, 71, 199-204. [CrossRef]

31. Nochur, S.V.; Demain, A.L.; Roberts, M.F. Carbohydrate utilization by Clostridium thermocellum: Importance of internal pH in regulating growth. Enzym. Microb. Technol. 1992, 14, 338-349. [CrossRef]

32. Patni, N.J.; Alexander, J.K. Utilization of Glucose by Clostridium thermocellum: Presence of Glucokinase and Other Glycolytic Enzymes in Cell Extracts. J. Bacteriol. 1971, 105, 220-225. [CrossRef] [PubMed]

33. Hernández, P.E. Transport of D-glucose in Clostridium thermocellum ATCC-27405. J. Gen. Appl. Microbiol. 1982, 28, 469-477. [CrossRef]

34. Strobel, H.J.; Caldwell, F.C.; Dawson, K.A. Carbohydrate Transport by the Anaerobic Thermophile Clostridium thermocellum LQRI. Appl. Environ. Microbiol. 1995, 61, 4012-4015. [CrossRef] [PubMed]

35. Dragosits, M.; Mattanovich, D. Adaptive laboratory evolution-Principles and applications for biotechnology. Microb. Cell Factories 2013, 12, 64. [CrossRef] [PubMed]

36. Conrad, T.M.; Lewis, N.; Palsson, B. Ø Microbial laboratory evolution in the era of genome-scale science. Mol. Syst. Biol. 2011, 7, 509. [CrossRef]

37. Tian, L.; Papanek, B.; Olson, D.G.; Rydzak, T.; Holwerda, E.K.; Zheng, T.; Zhou, J.; Maloney, M.; Jiang, N.; Giannone, R.J.; et al. Simultaneous achievement of high ethanol yield and titer in Clostridium thermocellum. Biotechnol. Biofuels 2016, 9, 1-11. [CrossRef] [PubMed]

38. Yayo, J.; Kuil, T.; Olson, D.G.; Lynd, L.R.; Holwerda, E.K.; van Maris, A.J.A. Laboratory Evolution and Reverse Engineering of Clostridium thermocellum for Growth on Glucose and Fructose. Appl. Environ. Microbiol. 2021, 87. [CrossRef]

39. Johnson, E.A.; Madia, A.; Demain, A.L. Chemically Defined Minimal Medium for Growth of the Anaerobic Cellulolytic Thermophile Clostridium thermocellum. Appl. Environ. Microbiol. 1981, 41, 1060-1062. [CrossRef]

40. Zhang, Y.; Lynd, L.R. Quantification of cell and cellulase mass concentrations during anaerobic cellulose fermentation: Development of an enzyme-linked immunosorbent assay-based method with application to Clostridium thermocellum batch cultures. Anal. Chem. 2003, 75, 219-227. [CrossRef]

41. Xiong, W.; Lin, P.P.; Magnusson, L.; Warner, L.; Liao, J.; Maness, P.-C.; Chou, K.J. $\mathrm{CO}_{2}$-fixing one-carbon metabolism in a cellulose-degrading bacterium Clostridium thermocellum. Proc. Natl. Acad. Sci. USA 2016, 113, 13180-13185. [CrossRef]

42. Zhang, Y.-H.P.; Cui, J.; Lynd, L.; Kuang, L.R. A Transition from Cellulose Swelling to Cellulose Dissolution byo-Phosphoric Acid: Evidence from Enzymatic Hydrolysis and Supramolecular Structure. Biomacromolecules 2006, 7, 644-648. [CrossRef] [PubMed]

43. Brice, L.A.S.; Shao, X.; Izquierdo, J.A.; Lynd, L.R. Optimization of Affinity Digestion for the Isolation of Cellulosomes from Clostridium thermocellum. Prep. Biochem. Biotechnol. 2013, 44, 206-216. [CrossRef] [PubMed]

44. Zhang, Y.H.P.; Hong, J.; Ye, X. Cellulase Assays. In Methods in Molecular Biology; Springer: Berlin/Heidelberg, Germany, 2009; Volume 581, pp. 213-231.

45. Ribeiro, L.F.; De Lucas, R.C.; Vitcosque, G.L.; Ribeiro, L.F.; Ward, R.J.; Rubio, M.V.; Damásio, A.R.; Squina, F.M.; Gregory, R.C.; Walton, P.H.; et al. A novel thermostable xylanase GH10 from Malbranchea pulchella expressed in Aspergillus nidulans with potential applications in biotechnology. Biotechnol. Biofuels 2014, 7, 115. [CrossRef]

46. Miller, G.L. Use of Dinitrosalicylic Acid Reagent for Determination of Reducing Sugar. Anal. Chem. 1959, 31, 426-428. [CrossRef]

47. Saqib, A.A.N.; Whitney, P.J. Differential behaviour of the dinitrosalicylic acid (DNS) reagent towards mono- and di-saccharide sugars. Biomass Bioenergy 2011, 35, 4748-4750. [CrossRef]

48. Robinson, M.D.; McCarthy, D.J.; Smyth, G.K. edgeR: A Bioconductor package for differential expression analysis of digital gene expression data. Bioinformatics 2010, 26, 139-140. [CrossRef]

49. Johnson, E.; Sakajoh, M.; Halliwell, G.; Madia, A.; Demain, A. Saccharification of Complex Cellulosic Substrates by the Cellulase System from Clostridium thermocellum. Appl. Environ. Microbiol. 1982, 43, 1125-1132. [CrossRef]

50. Bayer, E.; Shoham, Y.; Lamed, R. The cellulosome: An exocellular organelle for degrading plant cell wall polysaccharides. In Glycomicrobiology; Doyle, R., Ed.; Kluwer Academic/Plenum Publishers: Amsterdam, The Netherlands, 2000 ; pp. $387-439$.

51. Nataf, Y.; Bahari, L.; Kahel-Raifer, H.; Borovok, I.; Lamed, R.; Bayer, E.A.; Sonenshein, A.L.; Shoham, Y. Clostridium thermocellum cellulosomal genes are regulated by extracytoplasmic polysaccharides via alternative sigma factors. Proc. Natl. Acad. Sci. USA 2010, 107, 18646-18651. [CrossRef] [PubMed]

52. Riederer, A.; Takasuka, T.E.; Makino, S.-I.; Stevenson, D.M.; Bukhman, Y.; Elsen, N.L.; Fox, B.G. Global Gene Expression Patterns in Clostridium thermocellum as Determined by Microarray Analysis of Chemostat Cultures on Cellulose or Cellobiose. Appl. Environ. Microbiol. 2011, 77, 1243-1253. [CrossRef] [PubMed] 
53. Waeonukul, R.; Kosugi, A.; Tachaapaikoon, C.; Pason, P.; Ratanakhanokchai, K.; Prawitwong, P.; Deng, L.; Saito, M.; Mori, Y. Efficient saccharification of ammonia soaked rice straw by combination of Clostridium thermocellum cellulosome and Thermoanaerobacter brockii $\beta$-glucosidase. Bioresour. Technol. 2012, 107, 352-357. [CrossRef]

54. Koeck, D.; Koellmeier, T.; Zverlov, V.; Liebl, W.; Schwarz, W. Differences in biomass degradation between newly isolated environmental strains of Clostridium thermocellum and heterogeneity in the size of the cellulosomal scaffoldin. Syst. Appl. Microbiol. 2015, 38, 424-432. [CrossRef]

55. Sand, A.; Holwerda, E.K.; Ruppertsberger, N.M.; Maloney, M.; Olson, D.; Nataf, Y.; Borovok, I.; Sonenshein, A.L.; Bayer, E.A.; Lamed, R.; et al. Three cellulosomal xylanase genes in Clostridium thermocellumare regulated by both vegetative SigA ( $\sigma \mathrm{A})$ and alternative SigI6 ( $\sigma \mathrm{I} 6)$ factors. FEBS Lett. 2015, 589, 3133-3140. [CrossRef]

56. Xu, Q.; Resch, M.; Podkaminer, K.; Yang, S.; Baker, J.; Donohoe, B.; Wilson, C.; Klingeman, D.; Olson, D.; Decker, S.; et al. Dramatic Performance of Clostridium thermocellum Explained by Its Wide Range of Cellulase Modalities. Sci. Adv. 2016, 2, e1501254. [CrossRef] [PubMed]

57. Verbeke, T.J.; Garcia, G.M.; Elkins, J.G. The effect of switchgrass loadings on feedstock solubilization and biofuel production by Clostridium thermocellum. Biotechnol. Biofuels 2017, 10, 233. [CrossRef] [PubMed]

58. Kim, S.-K.; Himmel, M.E.; Bomble, Y.J.; Westpheling, J. Expression of a Cellobiose Phosphorylase from Thermotoga maritima in Caldicellulosiruptor bescii Improves the Phosphorolytic Pathway and Results in a Dramatic Increase in Cellulolytic Activity. Appl. Environ. Microbiol. 2018, 84, e02348-17. [CrossRef] [PubMed]

59. Lamed, R.; Kenig, R.; Morag, E.; Calzada, J.; De Micheo, F.; Bayer, E. Efficient Cellulose Solubilization by a Combined Cellulosome Beta-Glucosidase System. Appl. Biochem. Biotechnol. 1991, 27, 173-183. [CrossRef]

60. Zhou, J.; Olson, D.G.; Argyros, D.A.; Deng, Y.; van Gulik, W.M.; van Dijken, J.P.; Lynd, L.R. Atypical Glycolysis in Clostridium thermocellum. Appl. Environ. Microbiol. 2013, 79, 3000-3008. [CrossRef] [PubMed]

61. Thompson, R.A.; Layton, D.S.; Guss, A.; Olson, D.; Lynd, L.R.; Trinh, C.T. Elucidating central metabolic redox obstacles hindering ethanol production in Clostridium thermocellum. Metab. Eng. 2015, 32, 207-219. [CrossRef]

62. Olson, D.; Hörl, M.; Fuhrer, T.; Cui, J.; Zhou, J.; Maloney, M.I.; Amador-Noguez, D.; Tian, L.; Sauer, U.; Lynd, L.R. Glycolysis without pyruvate kinase in Clostridium thermocellum. Metab. Eng. 2017, 39, 169-180. [CrossRef]

63. Nataf, Y.; Yaron, S.; Stahl, F.; Lamed, R.; Bayer, E.A.; Scheper, T.-H.; Sonenshein, A.L.; Shoham, Y. Cellodextrin and Laminaribiose ABC Transporters in Clostridium thermocellum. J. Bacteriol. 2009, 191, 203-209. [CrossRef] [PubMed]

64. Rangel, A.E.T.; Croft, T.; Barrios, A.F.G.; Reyes, L.H.; Maness, P.-C.; Chou, K.J. Transcriptomic analysis of a Clostridium thermocellum strain engineered to utilize xylose: Responses to xylose versus cellobiose feeding. Sci. Rep. 2020, 10, 1-15. [CrossRef]

65. Biswas, R.; Wilson, C.M.; Giannone, R.J.; Klingeman, D.M.; Rydzak, T.; Shah, M.B.; Hettich, R.L.; Brown, S.D.; Guss, A.M. Improved growth rate in Clostridium thermocellum hydrogenase mutant via perturbed sulfur metabolism. Biotechnol. Biofuels 2017, 10, 1-10. [CrossRef]

66. Retchless, A.C.; Lawrence, J.G. Ecological Adaptation in Bacteria: Speciation Driven by Codon Selection. Mol. Biol. Evol. 2012, 29, 3669-3683. [CrossRef]

67. Plotkin, J.B.; Kudla, G. Synonymous but not the same: The causes and consequences of codon bias. Nat. Rev. Genet. 2010, 12, 32-42. [CrossRef] [PubMed]

68. Thakur, M.; Badugu, S.; Muniyappa, K. UvrA and UvrC Subunits of the Mycobacterium Tuberculosis UvrABC Excinuclease Interact Independently of UvrB and DNA. FEBS Lett. 2020, 594, 851-863. [CrossRef]

69. Elgrably-Weiss, M.; Schlosser-Silverman, E.; Rosenshine, I.; Altuvia, S. DeoT, a DeoR-type transcriptional regulator of multiple target genes. FEMS Microbiol. Lett. 2006, 254, 141-148. [CrossRef]

70. Soisson, S.; MacDougall-Shackleton, B.; Schleif, R.; Wolberger, C. The 1.6 A Crystal Structure of the AraC Sugar-Binding and Dimerization Domain Complexed with D-Fucose. J. Mol. Biol. 1997, 273, 226-237. [CrossRef]

71. Gallegos, M.-T.; Michán, C.; Ramos, J.L. The XylS/AraC family of regulators. Nucleic Acids Res. 1993, 21, 807-810. [CrossRef] 